\title{
SOLOS SOB VEGETAÇÃO DE RESTINGA NA ILHA DO CARDOSO (SP). I - CARACTERIZAÇÃO E CLASSIFICAÇÃO ${ }^{(1)}$
}

\author{
Felipe Haenel Gomes ${ }^{(2)}$, Pablo Vidal-Torrado ${ }^{(3)}$, Felipe Macías $^{(4)}$, \\ Bruno Gherardi ${ }^{(5)} \&$ Xosé Luiz Otero Perez $^{(4)}$
}

\begin{abstract}
RESUMO
A vegetação de restinga é uma formação típica que ocorre nas planícies costeiras arenosas da costa brasileira, principalmente sobre solos quartzosos e pobres em nutrientes. Neste trabalho, foram estudados solos sob vegetação de restinga na Ilha do Cardoso (SP), com o objetivo de fornecer subsídios para melhor entendimento de sua gênese e contribuir para o aprimoramento do Sistema Brasileiro de Classificação de Solos (SiBCS). Para isso, realizou-se uma caracterização físico-química e morfológica detalhada desses solos. Os resultados mostraram solos hidromórficos, arenosos, muito ácidos, com teores variáveis de MO, sendo a podzolização o principal processo pedogenético presente. A presença de materiais sulfídricos também ocorre em conseqüência da influência de material subjacente diferenciado, não guardando relação com a podzolização. Os principais fatores que influenciaram a distribuição dos solos foram a idade de estabilização do material de origem e a microtopografia, que reflete a influência do lençol freático. Os Espodossolos estudados são holocênicos e a podzolização é diretamente influenciada pela hidromorfia, sendo este o fator decisivo na gênese do horizonte espódico. O SiBCS mostrou falhas na classificação da ordem Espodossolos a partir do segundo nível categórico (subordem), sobretudo no que diz respeito ao acúmulo de Fe no horizonte espódico. Como a presença de sulfetos pode afetar parte dos solos estudados, se drenados, gerando horizontes sulfúricos, sugere-se a inserção
\end{abstract}

\footnotetext{
${ }^{(1)}$ Parte da Tese de Doutorado apresentada à Escola Superior de Agricultura "Luiz de Queiroz" - ESALQ/USP. Realizada com auxílio da CAPES e da FAPESP. Recebido para publicação em dezembro de 2005 e aprovado em julho de 2007.

${ }^{(2)}$ Pesquisador do Centro de Tecnologia Canavieira. Fazenda Santo Antonio s/n, Caixa Postal 169, CEP 13400-970 Piracicaba (SP). E-mail:felipehgomes@hotmail.com

${ }^{(3)}$ Professor do Departamento de Ciência do Solo, Escola Superior de Agricultura "Luiz de Queiroz" - ESALQ/USP. Av. Pádua Dias 11. CEP 13418-900 Piracicaba (SP). Bolsista do CNPq. E-mail: pablo@esalq.usp.br

(4) Professor do Departamento de Edafologia da Universidade de Santiago de Compostela. Campus Universitário Sur. Faculdade de Bioloxia. Espanha. E-mail: edfmac@usc.es; edajax@usc.es

${ }^{(5)}$ Estudante de Graduação do Departamento de Ciência do Solo, ESALQ/USP. Bolsista de Iniciação Científica da FAPESP. E-mail: brunogherardi@yahoo.com.br
} 
da denominação “tiônico” no quarto nível categórico desta ordem, além da adoção de um critério químico na distinção das subordens.

Termos de indexação: Espodossolo, podzolização, solos tiomórficos, vegetação de restinga.

\title{
SUMMARY: SOILS UNDER RESTINGA VEGETATION ON THE CARDOSO ISLAND (SP). I - CHARACTERIZATION AND CLASSIFICATION
}

\begin{abstract}
Restinga is a typical vegetation on quartzitic, sandy, nutrient-poor parent materials along the Brazilian coast. Soils under restinga vegetation on the Ilha do Cardoso (SP) were studied to understand their genesis and to improve the Brazilian Soil Classification System (SiBCS). Thus, a physical, chemical and detailed morphological characterization was carried out. The results evidenced aquic, sandy, very acid soils with variable organic matter content, in which podzolization is the main pedogenic process. Sulphidric materials also occur due to the influence of different underlying iron sulphide-bearing materials, not related to podzolization. The main factors that affect soil distribution are the age of parent material and the microtopography, which reflects the influence of the water table. The studied Spodosols are holocenic and podzolization depends on aquic conditions, which is determinant for the genesis of the spodic horizon. The SiBCS classification of the Spodosol order at the $2^{\text {nd }}$ category level (suborder) is misleading, mainly in relation to the accumulation of iron in the spodic horizon. Chemical criteria in the suborder definition of the SiBCS should be defined and the "thionic" qualifier at the $4^{\text {th }}$ category level should be included due to the possibility of formation of acid sulphate soils in artificially drained areas.
\end{abstract}

Index terms: Spodosols, podzolization, acid sulphate soils, restinga vegetation.

\section{INTRODUÇÃO}

De acordo com Suguio \& Tessler (1984), a denominação "restinga" é empregada na literatura brasileira com diferentes acepções, podendo ser usada tanto para designar vários tipos de depósitos litorâneos quanto outras feições costeiras, e até mesmo a vegetação. Neste último caso, designaria uma vegetação arbustivo-arbórea característica de zonas costeiras arenosas. Os diferentes tipos de vegetação ocorrentes nas restingas brasileiras variam desde formações herbáceas, passando por formações arbustivas, chegando a florestas cujo dossel não ultrapassa $20 \mathrm{~m}$ de altura (Silva, 1999). O termo utilizado neste trabalho será "vegetação de restinga" e corresponde a uma planície arenosa com vegetação arbórea.

Os solos sob vegetação de restinga são arenosos, quimicamente pobres, tendo como principal fonte de nutrientes o spray marinho (Araújo \& Lacerda, 1987; Leão \& Dominguez, 2000). Trabalhos realizados na costa brasileira mostram que, sob essa vegetação, as principais classes de solos encontradas são Espodossolos e Neossolos Quartzarênicos (Moura Filho, 1998; Gomes et al., 1998; Rossi, 1999); muitas vezes estes últimos apresentam incipiente processo de podzolização, levando-os a apresentar características intermediárias para Espodossolo.
Os Espodossolos (antigamente denominados Podzóis) são solos minerais, com seqüência de horizontes A-E-Bh e, ou, Bs e, ou, Bhs-C. São na maioria arenosos, sendo raras as citações de outras classes texturais. Os Neossolos Quartzarênicos (antigas Areias Quartzozas) são solos minerais de seqüência de horizontes A-C e diferem dos anteriores pela ausência de horizonte espódico. Sua localização em relação aos Espodossolos é de maior proximidade do mar, imediatamente após as praias, enquanto aqueles predominam em posições mais afastadas do mar, correspondentes às planícies costeiras denominadas "restingas" (Oliveira et al., 1992).

Em geral, os Espodossolos são encontrados mais freqüentemente em regiões sob clima boreal e vegetação de coníferas do hemisfério norte (Chesworth \& Macías, 1985; Courchesne \& Hendershot, 1997; Lundström et al., 2000; van Breemen \& Buurman, 2002). Fora desse clima, ocorrem em materiais de origem quartzosos e pobres, tanto sob clima temperado como tropical (van Breemen \& Buurman, 2002). Os que ocorrem em planícies arenosas sob clima tropical são morfologicamente similares àqueles encontrados nas regiões temperadas, porém sua gênese não é necessariamente igual (Andriesse, 1969).

Os Espodossolos tropicais são tipicamente hidromórficos, freqüentemente muito profundos, 
chegando a formar os Espodossolos "gigantes". Matéria orgânica dissolvida (MOD) e $\mathrm{Al}$ são dominantes nos horizontes B destes solos; a MOD contém apreciáveis teores de polissacarídeos, os quais não são precipitados via complexação com metais, sendo grande parte da MO precipitada fisicamente. Aliado a isso, os baixos teores de Fe nestes ambientes hidromórficos reduzem a precipitação química (van Breemen \& Buurman, 2002).

No Brasil, estudos sobre Espodossolos não são comuns, porém têm destaque os realizados em solos localizados na Amazônia que ocorrem em transições Espodossolo-Latossolo (Lucas et al., 1987; Bravard \& Righi, 1989; Dubroeucq \& Volkoff, 1998; Mafra et al., 2002). Em regiões costeiras, Gomes et al. (1998) estudaram restingas na região norte do Estado do Rio de Janeiro, encontrando Espodossolos e Neossolos Quartzarênicos intermediários para Espodossolo, assim como Moura Filho (1998) em solos na costa alagoana.

A escassez de estudos sobre Espodossolos no Brasil levou esta ordem a ser uma das menos estruturadas no Sistema Brasileiro de Classificação de Solos (SiBCS). Na sua classificação utilizam-se critérios derivados da World reference base for soil resources (FAO, 1994) e da Soil Taxonomy(Estados Unidos, 1994).

Este trabalho teve como objetivo realizar uma caracterização física, química e morfológica de solos sob vegetação de restinga, a fim de compreender os fatores que influem em sua gênese, bem como dar subsídios para o aprimoramento da ordem Espodossolos no Sistema Brasileiro de Classificação de Solos.

\section{MATERIAL E MÉTODOS}

\section{Meio físico}

A área em estudo está localizada na porção nordeste da Ilha do Cardoso (Figura 1), em uma parcela de 10 ha, sob vegetação de restinga, incluída no projeto "BIOTA - parcelas permanentes", inserida no Parque Estadual da Ilha do Cardoso.
A geologia da Ilha do Cardoso é composta basicamente por rochas cristalinas pré-cambrianas, com sedimentos quaternários de origem marinha em suas bordas (Petri \& Fúlfaro, 1970). Esses sedimentos são predominantemente holocênicos, relacionados à Transgressão Santos, e são compostos de areia fina e muito fina bem selecionada (Suguio \& Martin, 1978), situando-se nas partes externas expostas ao mar aberto, enquanto nas porções internas e protegidas predominam depósitos estuarinos de natureza arenoargilosa. Por outro lado, na porção norte da ilha, foi preservado um importante testemunho de depósitos arenosos pleistocênicos relacionados à Transgressão Cananéia (Suguio, 1993).

Segundo Melo \& Mantovani (1994), dados coletados no biênio 1990-1991 em altitudes mais baixas que 200 metros revelaram que a média das temperaturas mínimas está em torno de $19{ }^{\circ} \mathrm{C}$; a média das máximas, em torno de $27^{\circ} \mathrm{C}$; e a precipitação média anual, entre 1.800 e $2.000 \mathrm{~mm}$, com clima tipo Af, segundo o modelo de classificação climática de Köppen.

O mapa de solos ultradetalhado da parcela estudada (Figura 2) mostra quatro unidades de mapeamento diferentes. De modo geral, ocorrem Neossolos Quartzarênicos na porção norte e Espodossolos Ferrocárbicos e Organossolos Tiomórficos no restante da parcela. A ocorrência dos Neossolos próximo à atual linha de costa estaria relacionada à menor idade do material de origem, ao passo que os Espodossolos e Organossolos ocorrem em cotas ligeiramente mais elevadas, com pedogênese mais evidente. Foi impossível separar outras unidades de mapeamento, apesar do detalhe do mapa, devido à complexidade da sua ocorrência (Gomes \& Vidal-Torrado, 2005).

\section{Análise estrutural}

Com base no mapa de solos (Figura 2), foram traçadas duas transeções (H e 14), procurando abranger todas as classes de solos encontradas na parcela onde foram realizadas as análises estruturais, conforme o método de Boulet et al. (1982), descrevendo-

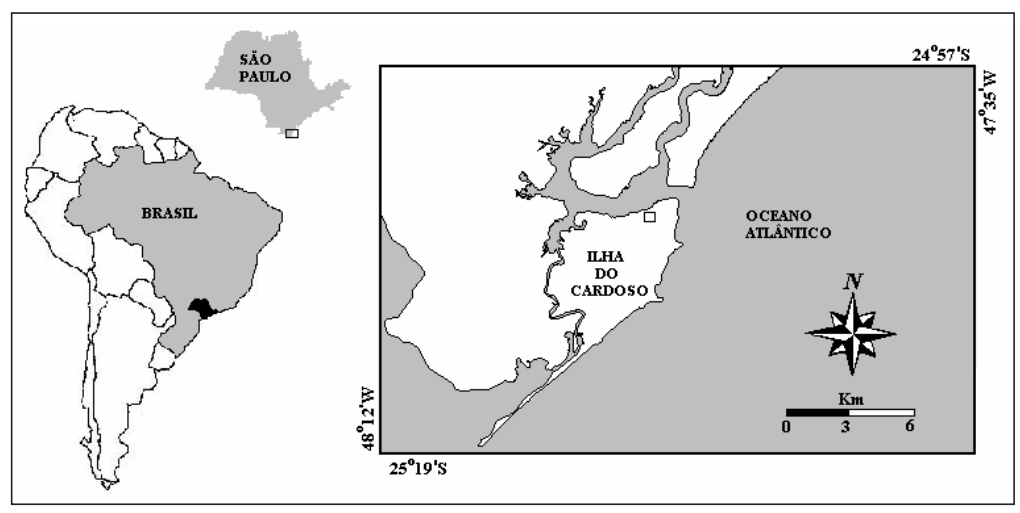

Figura 1. Localização da área estudada. 
se a morfologia de 20 em $20 \mathrm{~m}$, além das trincheiras, e aumentando o número de descrições entre os pontos quando necessário. Devido às condições de encharcamento da maior parte da área, foi utilizada a tradagem com um tubo de PVC envolvendo o trado, evitando, assim, o desmoronamento de material.

A área apresenta Neossolos Quartzarênicos ao norte, e a linha que divide estes com os restantes ocorre em uma antiga crista praial, onde há uma pequena elevação de cerca de $1 \mathrm{~m}$. Na porção oeste ocorre ligeira depressão, onde aparece o horizonte glei oriundo de material de origem diferenciado, o qual aparece também no perfil H16.

\section{Análises laboratoriais}

Foram escolhidos e analisados nove perfis representativos das duas transeções, conforme a figura 2. A descrição morfológica e a determinação dos horizontes foram realizadas de acordo com o descrito por Santos et al. (2005).

Foram coletadas amostras dos horizontes para caracterização física e química. As análises químicas e físicas foram feitas na TFSA (terra fina seca ao ar). A análise granulométrica foi realizada pelo método da dispersão, utilizando hidróxido de sódio $0,1 \mathrm{~mol} \mathrm{~L}^{-1}$, de acordo com Embrapa (1997). Para confirmar a presença de sulfetos, foi realizada a MEV (microscopia eletrônica de varredura) na fração densa (densidade $>2,89 \mathrm{~kg} \mathrm{dm}^{-3}$ ) da TFSA de um desses horizontes (2Cgj2 do perfil H16), utilizando o microscópio eletrônico LEO 4354 VP. Complementando a MEV, foi realizada a espectroscopia de energia dispersiva (EED) na amostra, com microssonda Oxford modelo 300.
Os cátions $\mathrm{Ca}^{2+}, \mathrm{Mg}^{2+} \mathrm{e} \mathrm{Al}^{3+}$ foram extraídos com solução $\mathrm{KCl} 1 \mathrm{~mol} \mathrm{~L}^{-1}$. A extração de $\mathrm{H}+\mathrm{Al}$ foi realizada com solução de acetato de cálcio $0,5 \mathrm{~mol} \mathrm{~L}^{-1}$ a $\mathrm{pH} 7,0$. Os teores de $\mathrm{P}, \mathrm{Na}^{+} \mathrm{e} \mathrm{K}^{+}$foram extraídos com solução de $\mathrm{H}_{2} \mathrm{SO}_{4}$ 0,0125 mol L-1 $+\mathrm{HCl} 0,05 \mathrm{~mol} \mathrm{~L}^{-1}$. Os teores de $\mathrm{Ca}^{2+}$ e $\mathrm{Mg}^{2+}$ foram determinados por espectroscopia de absorção atômica; $\mathrm{K}^{+} \mathrm{e} \mathrm{Na}^{+}$, por fotometria de chama; $\mathrm{e} \mathrm{Al}^{3+} \mathrm{eH}+\mathrm{Al}$, por titulometria. $\mathrm{O} \mathrm{pH}$ foi determinado em água, na proporção (peso) $1: 2,5$, após agitação e repouso de uma hora, por meio de potenciômetro. Todos esses procedimentos foram realizados de acordo com Embrapa (1997). O conteúdo de carbono orgânico total e o de S total foram determinados em analisadores elementares, sendo o Leco CNH-1000 para o carbono e o Leco 100 S-C 144DR para o S total.

A determinação de sulfato solúvel $\left(\mathrm{SO}_{4}{ }^{2-}\right)$ foi realizada por cromatografia iônica de alta resolução, utilizandose um equipamento Dionex. Foi utilizada a solução de equilíbrio, que é obtida através da relação solo:água $1: 20$, homogeneizando duas vezes ao dia, durante cinco dias, e extraindo o sobrenadante por filtração.

As seguintes extrações seletivas foram realizadas: extração com oxalato de amônio - feita de acordo com Buurman et al. (1996), na ausência de luz, com determinação de $\mathrm{Fe}$ e $\mathrm{Al}$ por espectroscopia de absorção atômica - determinação da densidade ótica no extrato $\left(\mathrm{DO}_{\text {ox }}\right)$ do mesmo, tendo o branco como referência, foi feita em colorímetro no comprimento de onda a $430 \mathrm{~nm}$, como recomendado para Espodossolos na Soil Taxonomy (Estados Unidos, 1999); e extração com ditionito-citrato de sódio - determinada por espectrofotometria de absorção atômica (Buurman et al., 1996).

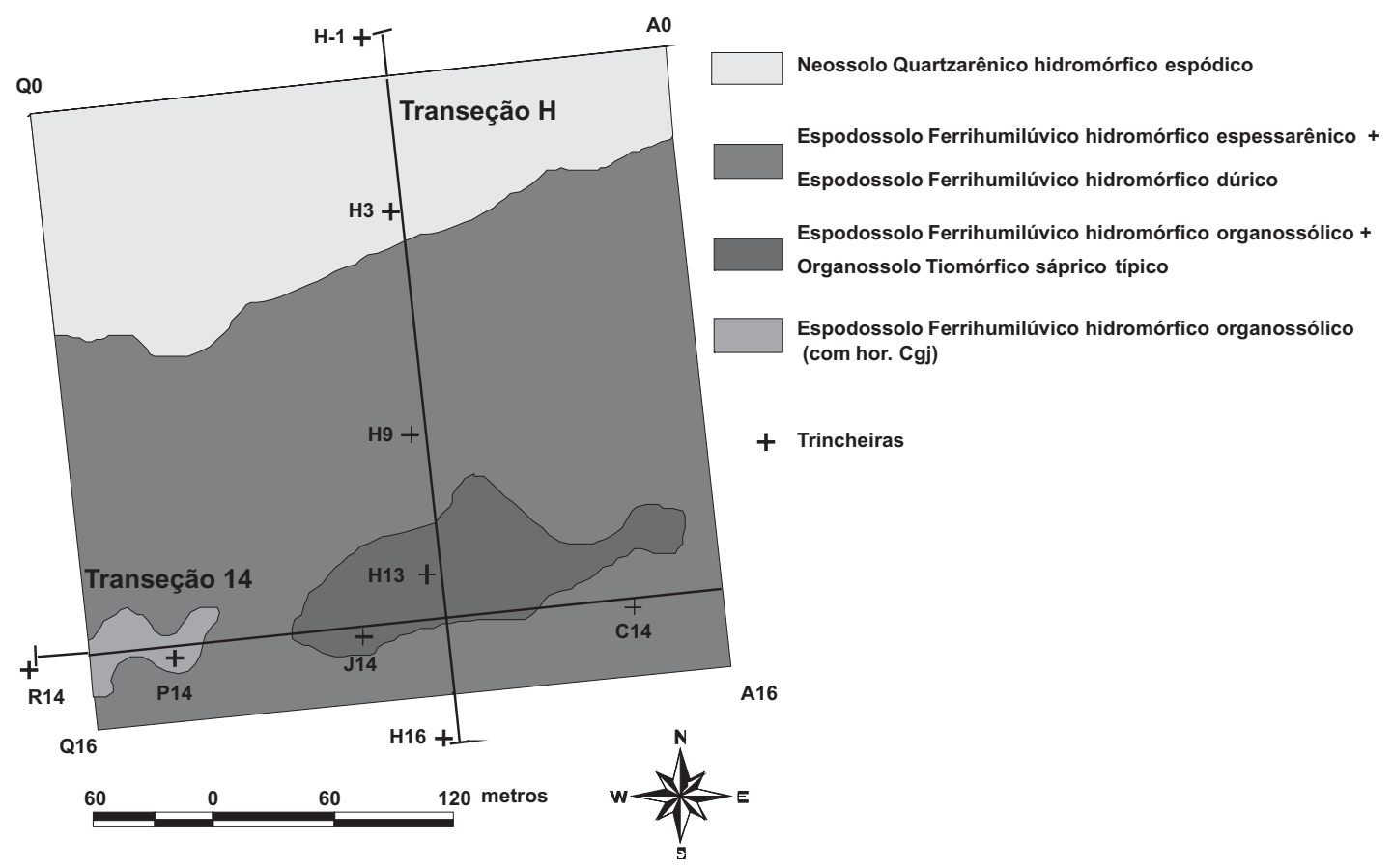

Figura 2. Mapa de solos indicando a localização das transeções e trincheiras amostradas. 
Foi realizado também o ataque sulfúrico de acordo com Embrapa (1997), conforme recomendação de Santos et al. (2003), nos horizontes com teores mais elevados de $\mathrm{Fe}$ e Al, utilizando-se de $\mathrm{H}_{2} \mathrm{SO}_{4} 1: 1 ;$ o Fe foi determinado por espectroscopia de absorção atômica, e o Al, por complexometria com CDTA.

A solução do solo foi obtida utilizando-se um lisímetro de tensão com cápsula porosa, submetido a pressão negativa. Após coleta, a solução foi armazenada em local refrigerado $\left(4^{\circ} \mathrm{C}\right)$, determinandose $\mathrm{oH}$ no dia seguinte.

Para estudo da idade de estabilização do material de origem, foram utilizadas pela técnica do ${ }^{14} \mathrm{C}$ duas amostras de material vegetal, de acordo com Pessenda \& Camargo (1991), utilizando uma raiz morta encontrada no perfil $\mathrm{H} 9$, a $180 \mathrm{~cm}$ de profundidade, e um tronco caído e soterrado no perfil $\mathrm{H} 3 \mathrm{a} 40 \mathrm{~cm}$ de profundidade.

\section{RESULTADOS}

A caracterização morfológica dos solos (Quadro 1) evidenciou a ocorrência de cores mais escuras (horizonte espódico) em profundidade, com ou sem presença de horizonte E, na maioria dos solos (Figura 3). A transição entre os horizontes espódicos e os suprajacentes foi geralmente ondulada e abrupta ou clara. Apenas os perfis H-1 e H3 não apresentaram horizonte espódico, embora no perfil H3 tenha ocorrido um horizonte $\mathrm{C} 1$ delgado com cores mais acinzentadas, indicando início de formação de um horizonte eluvial (horizonte E). Entre os perfis que apresentaram o horizonte espódico, apenas o Organossolo (perfil J14) não apresentou horizonte E. Nos Espodossolos, este horizonte apresentou variadas espessuras, desde $8 \mathrm{~cm}$ (perfil H16) até $67 \mathrm{~cm}$ (perfil H9).

Os horizontes espódicos apresentaram coloração mais escura no topo, que geralmente tornou-se mais brunada, com cores mais vivas, em profundidade. Não apresentaram unidades estruturais definidas, sendo o grau da estrutura descrito como grãos simples (não coerente) ou maciça (coerente), quando cimentados. Apenas alguns horizontes superficiais mais ricos em MO apresentaram agregados granulares de grau forte.

Os horizontes glei (2Cgj) e hístico (H) são os que apresentam consistência (quando molhada) de maior plasticidade e pegajosidade. Quanto à cimentação, ocorrem desde horizontes espódicos não cimentados até extremamente cimentados, geralmente no topo do horizonte glei.

A análise estrutural da transeção H (Figura 4) apresenta dois trechos distintos. O primeiro vai até o perfil $\mathrm{H} 3$, de cota mais baixa e sem o desenvolvimento do horizonte espódico, onde a datação do material vegetal (tronco enterrado a $40 \mathrm{~cm}$ de profundidade) na trincheira do perfil $\mathrm{H} 3$ mostrou que este tinha idade de $1.500 \pm 60$ anos AP (antes do presente). O segundo trecho, em cota mais elevada, apresentou o desenvolvimento deste horizonte, com espessuras e denominações variadas (Bhs ou Bs - dependendo da cor), chegando a apresentar endurecimento fraco (perfil H13).

A datação do material vegetal (raiz morta a $180 \mathrm{~cm}$ de profundidade) no perfil H9 mostrou idade de $4.690 \pm 80$ anos AP. Neste trecho, mais adiante, apresentou também, em uma condição de pequeno abaciamento, acúmulo de MO em superfície, originando o horizonte hístico (H13). A espessura do horizonte $\mathrm{E}$ também foi variada, sendo mais espesso onde apresentou maior elevação (antigas cristas praiais, como o perfil H9). No final da transeção, em posição mais baixa, ocorreu um horizonte $2 \mathrm{Cgj}$.

A transeção 14 (Figura 5) apresentou o horizonte espódico em toda a sua extensão; na porção intermediária ocorreu um horizonte hístico espesso, chegando a $70 \mathrm{~cm}$. No trecho final, próximo ao manguezal (perfil R14), este horizonte voltou a aparecer, porém em menor espessura. A cimentação ocorreu em grande parte do horizonte espódico na transeção, sendo variável de fraca a extremamente cimentada. O horizonte $\mathrm{E}$ mostrou comportamento semelhante ao observado na transeção $\mathrm{H}$, variando de acordo com a microtopografia.

Nas duas transeções, a ocorrência de horizonte hístico implicou maior espessura do Bhs sob ele e menor espessura ou ausência do horizonte Bs.

Em relação à granulometria (Quadro 2), são solos arenosos, com predominância da fração areia fina. Em profundidade, alguns solos apresentaram textura mais fina, notadamente o perfil H16 (horizontes 2Cgj1 e 2 Cgj2). Também é notado ligeiro incremento nos teores de argila nos horizontes espódicos e mesmo nos horizontes C (a partir de C4) dos Neossolos Quartzarênicos.

A caracterização química (Quadro 3) mostrou solos variando de forte a extremamente ácidos (Embrapa, 1999), com os valores de $\mathrm{pH}$ obtidos na TFSA diminuindo em profundidade. Os teores de $\mathrm{S}$ aumentaram sensivelmente em profundidade nos perfis H16, P14 e H3, acompanhado de decréscimo dos valores de $\mathrm{pH}$. Mesmo em outros perfis, como o J14, R14, H9 e H13, onde os teores de S em profundidade não aumentaram tanto, o $\mathrm{pH}$ diminuiu em mais de uma unidade. Os teores de $\mathrm{SO}_{4}{ }^{2-}$ seguiram tendência semelhante à de $\mathrm{S}$, sendo mais elevados também onde os valores de $\mathrm{pH}$ foram mais baixos. Os valores de $\mathrm{pH}$ obtidos na solução do solo mostraram tendência de serem mais elevados que os obtidos na TFSA, principalmente em profundidade. A CTC foi altamente dependente da MO, com elevados teores de $\mathrm{Al}$ trocável. A relação $\mathrm{C} / \mathrm{N}$ dos horizontes superficiais apresentou valor mínimo de 16,4, chegando a valores maiores que $50 \mathrm{em}$ alguns horizontes hísticos.

Os teores de $\mathrm{Fe}$ e $\mathrm{Al}$ nas extrações seletivas mostraram acúmulo desses elementos em subsuperficie 
Quadro 1. Dados morfológicos dos perfis de solos estudados na parcela permanente sob vegetação de mata de restinga do projeto BIOTA Parcelas Permanentes, Ilha do Cardoso, Cananéia (SP)

\begin{tabular}{|c|c|c|c|c|c|c|c|}
\hline \multirow{2}{*}{ Horizonte } & \multirow{2}{*}{ Profundidade } & \multicolumn{2}{|c|}{ Cor predominante } & \multirow{2}{*}{$\begin{array}{c}\text { Unidade } \\
\text { Estrutural }\end{array}$} & \multirow{2}{*}{$\operatorname{Grau}^{(1)}$} & \multirow{2}{*}{$\begin{array}{c}\text { Consistência } \\
\text { Molhada }^{(2)}\end{array}$} & \multirow{2}{*}{ Cimentação } \\
\hline & & Seca & Úmida & & & & \\
\hline
\end{tabular}

$\mathrm{m}$

$\begin{array}{ll}\text { A } & 0-0,20 \\ \text { C1 } & 0,20-0,55 \\ \text { C2 } & 0,55-0,75 \\ \text { C3 } & 0,75-0,85 \\ \text { C4 } & 0,85-1,05+\end{array}$

$\mathrm{A}$

C1

C2

Cg 1

$\mathrm{Cg} 2$

Cgj1

Cgj2

Cgj3

Cgj 4

A

$\mathrm{AE}$

E1

E2

Bhs

Bhsj1

Bhsj2

Bhsj3

Bhsj4

Bhsj5

Ho

$\mathrm{Hd}$

E

Bhsj1

Bhsj2

Bsj

Cgj
0-0,18

0,18-0,21

0,21-0,45

0,45-0,65

0,65-1,00

1,00-1,30

1,30-1,50

$1,50-1,80$

$1,80-2,10$
$0-0,20$

$0,20-0,28$

$(1,30-1,40)$

$0-0,10$
$0,10-0,28$
$0,28-0,38$
$0,38-0,55$
$0,55-0,75$
$0,75-1,30$
$1,30-1,65$

Munsell

H-1 - Neossolo Quartzarênico hidromórfico espódico

$\begin{array}{clllll}\text { 7,5YR 6/1 } & 5 \text { YR 3/1 } & \text { ausente } & \text { g. simples } & \text { n. pl. e n. peg. } & \text { não } \\ \text { 7,5YR 8/1 } & \text { 5 YR 6/1 } & \text { ausente } & \text { g. simples } & \text { n. pl. e n. peg. } & \text { não } \\ \text { 7,5YR 6/1 } & \text { 7,5 YR 3/1 } & \text { ausente } & \text { g. simples } & \text { n. pl. e n. peg. } & \text { não } \\ \text { 7,5YR 6/1 } & \text { 7,5 YR 3/2 } & \text { ausente } & \text { g. simples } & \text { n. pl. e n. peg. } & \text { não } \\ \text { 10YR 5/4 } & \text { 10 YR 2/2 } & \text { ausente } & \text { g. simples } & \text { n. pl. e n. peg. } & \text { não }\end{array}$

H3 - Neossolo Quartzarênico hidromórfico espódico

$\begin{array}{llllll}\text { 10YR 3/2 } & \text { 10YR } 2 / 1 & \text { granular } & \text { forte } & \text { lig. pl. e lig. peg. não } \\ \text { 7,5YR 6/1 } & \text { 10YR 4/2 } & \text { ausente } & \text { g. simples } & \text { n. pl. e n. peg. } & \text { não } \\ \text { 10YR 6/4 } & \text { 10YR } 3 / 4 & \text { ausente } & \text { g. simples } & \text { n. pl. e n. peg. } & \text { não } \\ \text { 10YR 5/2 } & \text { 10YR 4/2 } & \text { ausente } & \text { g. simples } & \text { n. pl. e n. peg. } & \text { não } \\ \text { 10YR 5/3 } & \text { 10YR 3/2 } & \text { ausente } & \text { g. simples } & \text { n. pl. e n. peg. } & \text { não } \\ \text { 10YR 6/3 } & \text { 10YR 4/2 } & \text { ausente } & \text { g. simples } & \text { n. pl. e n. peg. } & \text { não } \\ \text { 10YR 6/2 } & \text { 10YR 4/2 } & \text { ausente } & \text { g. simples } & \text { n. pl. e n. peg. } & \text { não } \\ \text { 10YR 6/1 } & \text { 10YR 5/1 } & \text { ausente } & \text { g. simples } & \text { n. pl. e n. peg. } & \text { não } \\ \text { 10YR 4/2 } & 10 Y R 3 / 2 & \text { ausente } & \text { g. simples } & \text { n. pl. e n. peg. } & \text { não }\end{array}$

H9 - Espodossolo Ferrrihumilúvico hidromórfico espessarênico $10 \mathrm{YR} 5 / 1$

10 YR 4/1 ausente

g. simples n. pl. e n. peg.

não

10YR 6/1

10YR 4/1 ausente

g. simples

n. pl. e n. peg.

7,5YR 7/1 $10 \mathrm{YR}$ 5/1

ausente

g. simples

n. pl. e n. peg.

g. simples

n. pl. e n. peg.

10YR $3 / 2$

$10 \mathrm{YR} 3 / 1$

g. simples

n. pl. e n. peg.

10YR $4 / 2$

$10 \mathrm{YR} 2 / 2$

ausente

g. simples

n. pl. e n. peg.

10YR 5/3

$10 \mathrm{YR} 4 / 2$ ausente

g. simples n. pl. e n. peg.

10YR 5/2

$10 \mathrm{YR} \mathrm{2/1}$

ausente

g. simples

n. pl. e n. peg.

10YR 4/2

$10 \mathrm{YR} 3 / 2$

ausente

g. simples

n. pl. e n. peg.

g. simples

n. pl. e n. peg.

10YR $4 / 2$

10 YR 2/1 ausente

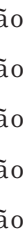

H13 - Espodossolo Ferrihumilúvico hidromórfico organossólico

\begin{abstract}
5YR 3/1
\end{abstract}
10YR 4/1

5 YR $2,5 / 1$

$5 \mathrm{YR} 2,5 / 1$

fibras

10YR 7/2

10YR 5/2

ausente

-

maciça

n. pl. e n. peg.

10YR 3/2

10YR 2/1

10YR 4/3

10YR 2/2

10 YR $4 / 3$

10YR $3 / 4$

10YR 6/2 ausente

ausente

ausente

ausente g. simples

maciça

g. simples

g. simples

g. simples pl. e peg.

n. pl. e n. peg. não

n. pl. e n. peg. fracamente

n. pl. e n. peg.

n. pl. e n. peg.

n. pl. e n. peg. 


\section{Quadro 1. Continuação}

\begin{tabular}{|c|c|c|c|c|c|c|c|}
\hline \multirow{2}{*}{ Horizonte } & \multirow{2}{*}{ Profundidade } & \multicolumn{2}{|c|}{ Cor predominante } & \multirow{2}{*}{$\begin{array}{l}\text { Unidade } \\
\text { Estrutural }\end{array}$} & \multirow{2}{*}{$\operatorname{Grau}^{(1)}$} & \multirow{2}{*}{$\begin{array}{c}\text { Consistência } \\
\text { Molhada }^{(2)}\end{array}$} & \multirow{2}{*}{ Cimentação } \\
\hline & & Seca & Úmida & & & & \\
\hline \multicolumn{8}{|c|}{ Munsell } \\
\hline \multicolumn{8}{|c|}{ H16 - Espodossolo Ferrihumilúvico hidromórfico arênico } \\
\hline A & $0-0,10$ & 10YR 3/1 & 10YR $2 / 1$ & granular & forte & lig. pl. e lig. peg. & não \\
\hline $\mathrm{AE}$ & $0,10-0,15$ & 10YR 6/1 & $10 \mathrm{YR} 4 / 1$ & ausente & g. simples & n. pl. e n. peg. & não \\
\hline $\mathrm{E}$ & $0,15-0,23$ & 10YR 6/1 & $10 \mathrm{YR} 4 / 2$ & ausente & g. simples & n. pl. e n. peg. & não \\
\hline Bhs & $0,23-0,40$ & 10YR 4/2 & 10YR 3/1 & ausente & g. simples & n. pl. e n. peg. & não \\
\hline Bhsj1 & $0,40-0,54$ & 10YR $3 / 2$ & $10 \mathrm{YR} 2 / 2$ & ausente & g. simples & n. pl. e n. peg. & não \\
\hline Bhsj2 & $0,54-0,62$ & 10YR $2 / 2$ & $10 \mathrm{YR} 3 / 2$ & ausente & g. simples & n. pl. e n. peg. & não \\
\hline $2 \mathrm{Cgj} 1$ & $0,62-0,80$ & $2,5 \mathrm{Y} 3 / 1$ & G1 3/10Y & ausente & maciça & lig. pl. e peg. & não \\
\hline $2 \mathrm{Cgj} 2$ & $0,80-1,60+$ & G1 4/10Y & G1 $2,5 / 10 \mathrm{Y}$ & ausente & maciça & pl. e peg. & não \\
\hline \multicolumn{8}{|c|}{ C14 - Espodossolo Ferrihumilúvico hidromórfico dúrico } \\
\hline A & $0-0,15$ & 10YR 4/1 & 10YR $3 / 2$ & ausente & g. simples & n. pl. e n. peg. & não \\
\hline $\mathrm{AE}$ & $0,15-0,20$ & 10YR $7 / 1$ & $10 \mathrm{YR} 5 / 1$ & ausente & g. simples & n. pl. e n. peg. & não \\
\hline $\mathrm{E}$ & $0,20-0,50$ & 10YR 8/1 & 10YR $7 / 1$ & ausente & g. simples & n. pl. e n. peg. & não \\
\hline Bhs & $0,50-0,58$ & 10YR $4 / 2$ & 10YR $2 / 1$ & ausente & g. simples & n. pl. e n. peg. & não \\
\hline Bhsm 1 & $0,58-0,75$ & 10YR $3 / 2$ & $10 \mathrm{YR} 2 / 1$ & ausente & maciça & n. pl. e n. peg. & fortemente \\
\hline Bhsm2 & $0,75-1,00$ & $10 \mathrm{YR} 4 / 3$ & $10 \mathrm{YR} 3 / 3$ & ausente & maciça & n. pl. e n. peg. & fortemente \\
\hline Bs 1 & $1,00-1,20$ & 10YR 5/3 & $10 \mathrm{YR} 4 / 4$ & ausente & g. simples & n. pl. e n. peg. & não \\
\hline $\mathrm{Bs} 2$ & $1,20-1,60$ & $2,5 \mathrm{Y} 6 / 6$ & $10 \mathrm{YR} 4 / 4$ & ausente & g. simples & n. pl. e n. peg. & não \\
\hline $\mathrm{Bs} 3$ & $1,60-1,80$ & $2,5 \mathrm{Y} 6 / 4$ & $10 \mathrm{YR} 5 / 4$ & ausente & g. simples & n. pl. e n. peg. & não \\
\hline $\mathrm{Bs} 4$ & $1,80-2,10$ & 10YR 5/3 & $10 \mathrm{YR} 4 / 3$ & ausente & g. simples & n. pl. e n. peg. & não \\
\hline $\mathrm{C}$ & $2,10-2,40$ & 10YR 6/3 & $10 \mathrm{YR} 5 / 4$ & Ausente & g. simples & n. pl. e n. peg. & não \\
\hline \multicolumn{8}{|c|}{ J14 - Organossolo Tiomórfico sáprico típico } \\
\hline $\mathrm{Hd} 1$ & $0-0,20$ & $5 \mathrm{YR} 3 / 1$ & $5 \mathrm{YR} 2,5 / 1$ & ausente & maciça & pl. e peg. & não \\
\hline $\mathrm{Hd} 2$ & $0,20-0,50$ & $5 \mathrm{YR} 3 / 1$ & $5 \mathrm{YR} 2,5 / 1$ & ausente & maciça & pl. e peg. & não \\
\hline $\mathrm{Hd} 3$ & $0,50-0,60$ & $2,5 \mathrm{YR} 4 / 3$ & 7,5 YR $2,5 / 2$ & ausente & maciça & pl. e peg. & não \\
\hline $\mathrm{Hd} 4$ & $0,60-0,70$ & 7,5 YR $2,5 / 1$ & $5 \mathrm{YR} 2,5 / 1$ & ausente & maciça & pl. e peg. & não \\
\hline Bhsj1 & $0,70-1,00$ & 7,5YR $3 / 3$ & 10YR $2 / 1$ & ausente & g. simples & n. pl. e n. peg. & fracamente \\
\hline Bhsj2 & $1,00-1,30+$ & $10 \mathrm{YR} 5 / 2$ & $10 \mathrm{YR} 2 / 1$ & ausente & g. simples & n. pl. e n. peg. & não \\
\hline \multicolumn{8}{|c|}{ P14 - Espodossolo Ferrihumilúvico hidromórfico organossólico } \\
\hline Но & $0-0,12$ & $5 Y R 3 / 2$ & 5 YR $2,5 / 2$ & fibras & - & n. pl. e n. peg. & não \\
\hline $\mathrm{Hd}$ & $0,12-0,22$ & 10YR $3 / 1$ & 10YR $2 / 1$ & ausente & maciça & lig. pl. e lig. peg. & não \\
\hline $\mathrm{E} 1$ & $0,22-0,40$ & 10YR 7/1 & $10 \mathrm{YR} 5 / 1$ & ausente & g. simples & n. pl. e n. peg. & não \\
\hline $\mathrm{E} 2$ & $0,40-0,60$ & $10 \mathrm{YR} 5 / 2$ & $10 \mathrm{YR} 3 / 2$ & ausente & g. simples & n. pl. e n. peg. & não \\
\hline Bhsj1 & $0,60-0,95$ & $10 \mathrm{YR} 4 / 3$ & $10 \mathrm{YR} 3 / 3$ & ausente & g. simples & n. pl. e n. peg. & não \\
\hline Bhsj2 & $0,95-1,03$ & $10 Y R \quad 4 / 4$ & 10YR $2 / 2$ & ausente & maciça & n. pl. e n. peg. & fortemente \\
\hline $2 \mathrm{Cgj}$ & $1,03-1,40+$ & G1 5/10Y & G1 $3 / 10 \mathrm{Y}$ & ausente & maciça & lig. pl. e lig. peg. & não \\
\hline \multicolumn{8}{|c|}{ R14 - Espodossolo Ferrihumilúvico hidromórfico organossólico } \\
\hline Но & $0-0,07$ & $5 Y R 3 / 2$ & $5 \mathrm{YR} 2,5 / 2$ & fibras & - & n. pl. e n. peg. & não \\
\hline A & $0,07-0,14$ & 10YR 6/1 & 10YR $3 / 2$ & ausente & g. simples & n. pl. e n. peg. & não \\
\hline $\mathrm{E}$ & $0,14-0,23$ & 10YR $6 / 2$ & 10YR $3 / 2$ & ausente & g. simples & n. pl. e n. peg. & não \\
\hline Bhsj & $0,23-0,30$ & $10 \mathrm{YR} 4 / 2$ & $10 \mathrm{YR} 2 / 1$ & ausente & g. simples & n. pl. e n. peg. & não \\
\hline Bhsmj & $0,30-0,45$ & $10 \mathrm{YR} 2 / 2$ & $10 \mathrm{YR} 2 / 1$ & ausente & maciça & n. pl. e n. peg. & extremamente \\
\hline $\mathrm{Cgj}$ & $0,45-0,60+$ & 10YR 6/1 & $10 \mathrm{YR} 4 / 1$ & ausente & g. simples & n. pl. e n. peg. & não \\
\hline
\end{tabular}

${ }^{(1)}$ g. simples: grãos simples. ${ }^{(2)}$ n. pl.: não plástico; n. peg.: não pegajosa; lig. pl.: ligeiramente plástico; lig. peg.: ligeiramente pegajosa; pl: plástico; peg.: pegajosa. 

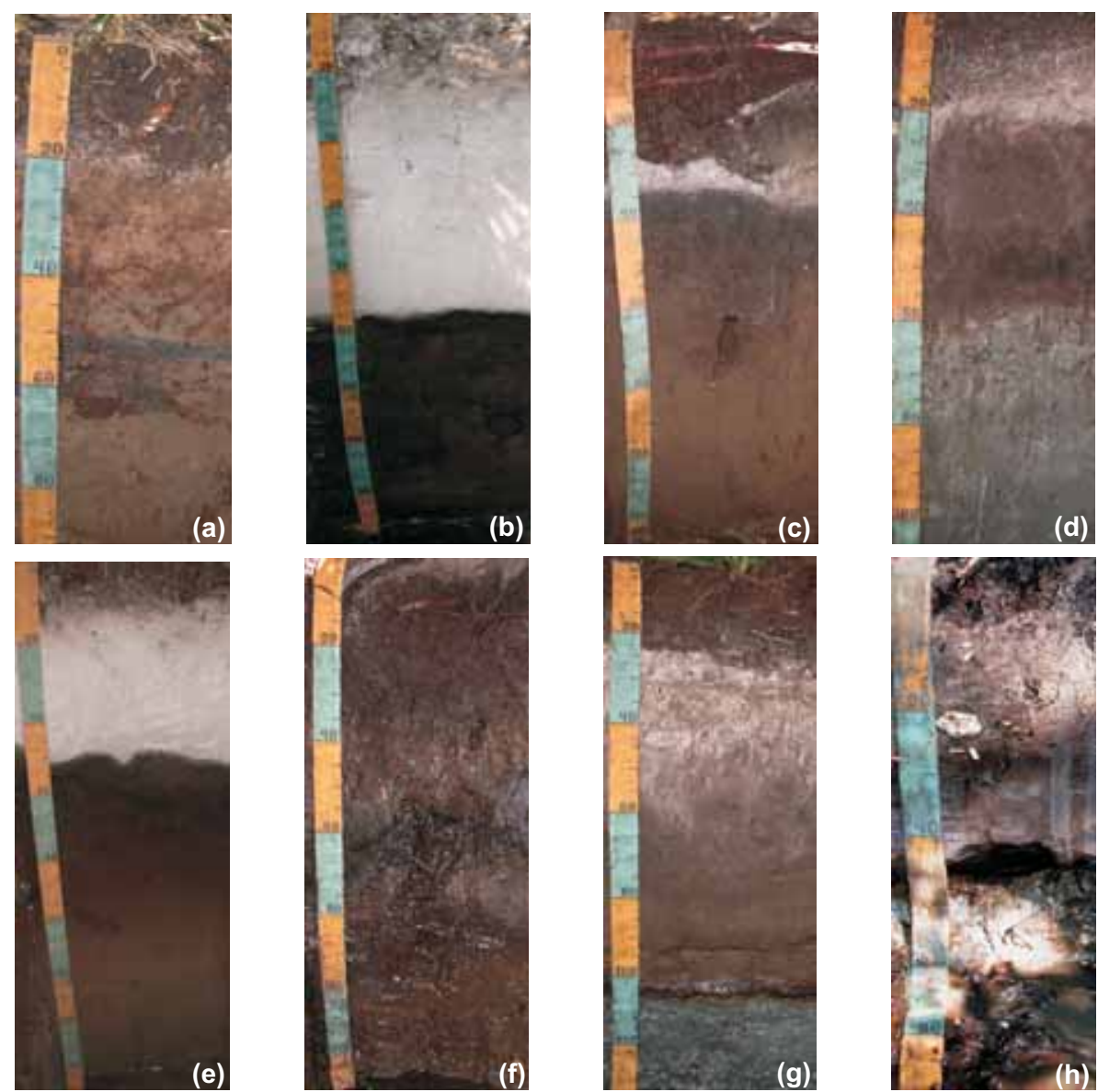

Figura 3. Fotos dos perfis estudados, evidenciando a variação de horizontes dos solos estudados sob vegetação de mata de restinga na Ilha do Cardoso, Cananéia, SP. Na transeção H, o perfil $\mathrm{H} 16$ apresenta o horizonte 2Cgj com descontinuidade evidente (d), assim como o perfil P14 da transeção 14 (g). No perfil R14 (h), o ortstein está sobre o horizonte Cgj, erodido.

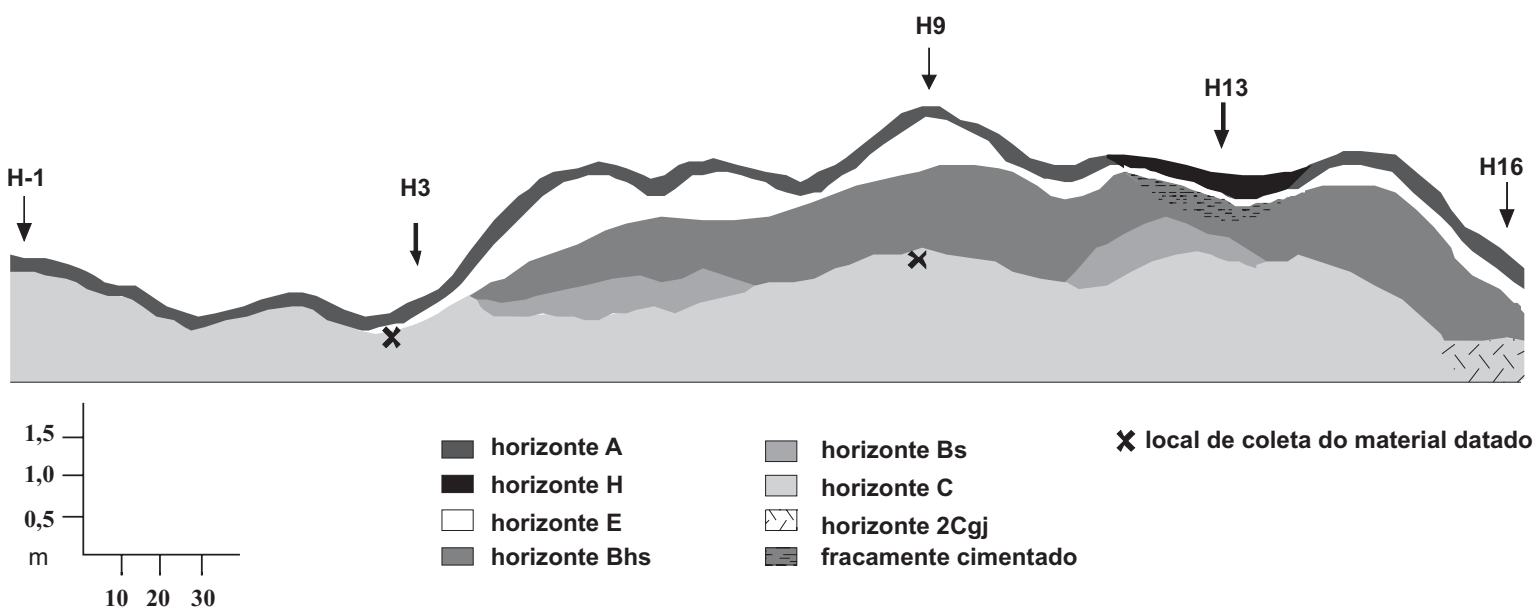

Figura 4. Estrutura da transeção H dos solos estudados sob vegetação de mata de restinga na Ilha do Cardoso, Cananéia (SP).

e predominância do $\mathrm{Al}$ em relação ao Fe. Os valores de $\mathrm{DO}_{\text {ox }}$ apresentaram aumento em subsuperfície tanto nos Neossolos como nos horizontes espódicos, com os maiores valores no topo destes horizontes, decrescendo mais abaixo.
A microscopia eletrônica de varredura (MEV) mostrou, nos horizontes $2 \mathrm{Cgj}$, a presença de piritas, evidenciadas pela espectroscopia de energia dispersiva (EDS), na forma "framboidal" (Figura 6), já em processo de oxidação. 
Quadro 2. Granulometria dos perfis de solos estudados na parcela permanente sob vegetação de mata de restinga do projeto BIOTA Parcelas Permanentes, Ilha do Cardoso, Cananéia (SP)

\begin{tabular}{|c|c|c|c|c|c|c|c|c|c|}
\hline \multirow{2}{*}{ Horizonte } & \multirow{2}{*}{ Profundidade } & \multicolumn{5}{|c|}{$\operatorname{Areia}^{(1)}$} & \multirow{2}{*}{ Silte } & \multirow{2}{*}{ Argila } & \multirow{2}{*}{ Classe textural } \\
\hline & & MG & G & M & F & MF & & & \\
\hline
\end{tabular}
$\mathrm{g} \mathrm{kg}^{-1}$

\begin{tabular}{llrllrrrrr} 
& \multicolumn{1}{c}{ H1 Neossolo Quartzarênico hidromórfico espódico } \\
A & $0-0,20$ & 0 & 0 & 20 & 920 & 20 & 0 & 40 & Areia \\
C1 & $0,20-0,55$ & 0 & 0 & 30 & 960 & 10 & 0 & 0 & Areia \\
C2 & $0,55-0,75$ & 0 & 0 & 30 & 940 & 30 & 0 & 0 & Areia \\
C3 & $0,75-0,85$ & 0 & 0 & 20 & 940 & 20 & 0 & 20 & Areia \\
C4 & $0,85-1,05+$ & 0 & 0 & 10 & 930 & 20 & 0 & 40 & Areia
\end{tabular}

H3 - Neossolo Quartzarênico hidromórfico espódico

$\begin{array}{llllrrrrrl}\text { A } & 0-0,18 & 0 & 0 & 80 & 770 & 60 & 40 & 50 & \text { Areia } \\ \mathrm{C} 1 & 0,18-0,21 & 0 & 0 & 40 & 910 & 20 & 10 & 20 & \text { Areia } \\ \mathrm{C} 2 & 0,21-0,45 & 0 & 0 & 10 & 940 & 30 & 0 & 20 & \text { Areia } \\ \mathrm{Cg} 1 & 0,45-0,65 & 0 & 0 & 10 & 880 & 70 & 30 & 10 & \text { Areia } \\ \mathrm{Cg} 2 & 0,65-1,00 & 0 & 0 & 0 & 900 & 50 & 20 & 30 & \text { Areia } \\ \mathrm{Cgj} 1 & 1,00-1,30 & 0 & 0 & 10 & 800 & 40 & 100 & 50 & \text { Areia franca } \\ \mathrm{Cgj} 2 & 1,30-1,50 & 0 & 0 & 0 & 880 & 40 & 40 & 40 & \text { Areia } \\ \mathrm{Cgj} 3 & 1,50-1,80 & 0 & 0 & 0 & 880 & 40 & 20 & 60 & \text { Areia } \\ \mathrm{Cgj} 4 & 1,80-2,10 & 0 & 0 & 0 & 850 & 50 & 20 & 80 & \text { Areia }\end{array}$

H8 - Espodossolo Ferrrihumilúvico hidromórfico espessarênico

$\begin{array}{llllrrrrrl}\text { A } & 0-0,20 & 0 & 0 & 10 & 950 & 10 & 0 & 30 & \text { Areia } \\ \text { AE } & 0,20-0,28 & 0 & 0 & 10 & 960 & 10 & 0 & 20 & \text { Areia } \\ \text { E1 } & 0,28-0,41 & 0 & 0 & 10 & 960 & 10 & 0 & 20 & \text { Areia } \\ \text { E2 } & 0,41-0,95 & 0 & 0 & 0 & 970 & 10 & 0 & 20 & \text { Areia } \\ \text { Bhs } & 0,95-1,03 & 0 & 0 & 0 & 920 & 20 & 10 & 50 & \text { Areia } \\ \text { Bhsj1 } & 1,03-1,35 & 0 & 0 & 0 & 920 & 30 & 10 & 40 & \text { Areia } \\ & (1,30-1,40) & & & & & & & & \\ \text { Bhsj2 } & 1,35-1,80 & 0 & 0 & 0 & 930 & 30 & 10 & 30 & \text { Areia } \\ \text { Bhsj3 } & 1,80-2,10 & 0 & 0 & 20 & 790 & 10 & 120 & 60 & \text { Areia franca } \\ \text { Bhsj4 } & 2,10-2,50 & 0 & 0 & 110 & 790 & 20 & 40 & 40 & \text { Areia } \\ \text { Bhsj5 } & 2,50-2,80 & 0 & 0 & 10 & 890 & 20 & 20 & 60 & \text { Areia }\end{array}$

H13 - Espodossolo Ferrihumilúvico hidromórfico organossólico

$\begin{array}{llrrrrrrrl}\text { Ho } & 0-0,10 & \ldots & \ldots & \ldots & \ldots & \ldots & \ldots & \ldots & \ldots \\ \text { Hd } & 0,10-0,28 & \ldots & \ldots & \ldots & \ldots & \ldots & \ldots & \ldots & \ldots \\ \text { E } & 0,28-0,38 & 0 & 0 & 10 & 940 & 20 & 0 & 30 & \text { Areia } \\ \text { Bhsj1 } & 0,38-0,55 & 0 & 0 & 0 & 940 & 30 & 0 & 30 & \text { Areia } \\ \text { Bhsj2 } & 0,55-0,75 & 0 & 0 & 0 & 930 & 30 & 0 & 40 & \text { Areia } \\ \text { Bsj } & 0,75-1,30 & 0 & 0 & 10 & 890 & 50 & 10 & 40 & \text { Areia } \\ \text { Cgj } & 1,30-1,65 & 0 & 0 & 0 & 860 & 40 & 60 & 40 & \text { Areia }\end{array}$

Continua... 
Quadro 2. Continuação

\begin{tabular}{|c|c|c|c|c|c|c|c|c|c|}
\hline \multirow{2}{*}{ Horizonte } & \multirow{2}{*}{ Profundidade } & \multicolumn{5}{|c|}{$\operatorname{Areia}^{(1)}$} & \multirow{2}{*}{ Silte } & \multirow{2}{*}{ Argila } & \multirow{2}{*}{ Classe textural } \\
\hline & & MG & G & M & F & MF & & & \\
\hline
\end{tabular}

$\mathrm{m}$

$\mathrm{g} \mathrm{kg}^{-1}$

H16 - Espodossolo Ferrihumilúvico hidromórfico arênico

\begin{tabular}{|c|c|c|c|c|c|c|c|c|c|}
\hline A & $0-0,10$ & 0 & 0 & 10 & 910 & 40 & 0 & 40 & Areia \\
\hline $\mathrm{AE}$ & $0,10-0,15$ & 0 & 0 & 10 & 930 & 30 & 0 & 30 & Areia \\
\hline E & $0,15-0,23$ & 0 & 0 & 0 & 950 & 20 & 0 & 30 & Areia \\
\hline Bhs & $0,23-0,40$ & 0 & 0 & 0 & 950 & 20 & 0 & 30 & Areia \\
\hline Bhsj1 & $0,40-0,54$ & 0 & 0 & 0 & 930 & 20 & 0 & 50 & Areia \\
\hline Bhsj2 & $0,54-0,62$ & 0 & 0 & 0 & 920 & 20 & 10 & 50 & Areia \\
\hline $2 \mathrm{Cgj} 1$ & $0,62-0,80$ & 0 & 0 & 0 & 490 & 60 & 130 & 320 & $\begin{array}{l}\text { Franco-argilo- } \\
\text { arenosa }\end{array}$ \\
\hline $2 \mathrm{Cgj} 2$ & $0,80-1,60+$ & 0 & 0 & 0 & 310 & 80 & 160 & 450 & Argila \\
\hline
\end{tabular}

14 - Espodossolo Ferrihumilúvico hidromórfico dúrico

$\begin{array}{lllllllll}\text { A } & 0-0,15 & 0 & 0 & 10 & 910 & 40 & 0 & 40\end{array}$

$\begin{array}{lllllllll}\text { AE } & 0,15-0,20 & 0 & 0 & 0 & 930 & 50 & 0 & 20\end{array}$

$\begin{array}{lllllllll}\mathrm{E} & 0,20-0,50 & 0 & 0 & 0 & 930 & 50 & 10 & 10\end{array}$

$\begin{array}{lllllllll}\text { Bhs } 1 & 0,50-0,58 & 0 & 0 & 0 & 860 & 60 & 0 & 80\end{array}$

$\begin{array}{lllllllll}\text { Bhs2 } & 0,58-0,75 & 0 & 0 & 0 & 860 & 50 & 0 & 90\end{array}$

$\begin{array}{lllllllll}\text { Bhs3 } & 0,75-1,00 & 0 & 0 & 0 & 890 & 30 & 10 & 70\end{array}$

$\begin{array}{lllllllll}\text { Bs } 1 & 1,00-1,20 & 0 & 0 & 0 & 880 & 30 & 30 & 60\end{array}$

$\begin{array}{lllllllll}\text { Bs2 } 2 & 1,20-1,60 & 0 & 0 & 0 & 890 & 40 & 20 & 50\end{array}$

$\begin{array}{lllllllll}\text { Bs3 } 3,60-1,80 & 0 & 0 & 0 & 900 & 40 & 10 & 50\end{array}$

$\begin{array}{lllllllll}\text { Bs4 } 4,80-2,10 & 0 & 0 & 10 & 860 & 30 & 60 & 40\end{array}$

C $2,10-2,40$

$\begin{array}{lllllll}0 & 0 & 30 & 850 & 20 & 40 & 60\end{array}$

J14 - Organossolo Tiomórfico sáprico típico

\begin{tabular}{|c|c|c|c|c|c|c|c|c|c|}
\hline Hd 1 & $0-0,20$ & $\ldots$ & $\ldots$ & $\ldots$ & $\ldots$ & $\ldots$ & $\ldots$ & $\ldots$ & $\ldots$ \\
\hline $\mathrm{Hd} 2$ & $0,20-0,50$ & $\ldots$ & $\ldots$ & $\ldots$ & $\ldots$ & $\ldots$ & $\ldots$ & $\ldots$ & $\ldots$ \\
\hline $\mathrm{Hd} 3$ & $0,50-0,60$ & $\ldots$ & $\ldots$ & $\ldots$ & $\ldots$ & $\ldots$ & $\ldots$ & $\ldots$ & $\ldots$ \\
\hline $\mathrm{Hd} 4$ & $0,60-0,70$ & $\ldots$ & $\ldots$ & $\ldots$ & $\ldots$ & $\ldots$ & $\ldots$ & $\ldots$ & $\ldots$ \\
\hline Bhsj1 & $0,70-1,00$ & 0 & 0 & 0 & 940 & 30 & 0 & 30 & Areia \\
\hline Bhsj2 & $1,00-1,30+$ & 0 & 0 & 0 & 880 & 60 & 0 & 60 & Areia \\
\hline
\end{tabular}

P14 - Espodossolo Ferrihumilúvico hidromórfico organossólico

\begin{tabular}{|c|c|c|c|c|c|c|c|c|c|}
\hline Ho & $0-0,12$ & $\ldots$ & $\ldots$ & $\cdots$ & $\ldots$ & $\ldots$ & $\cdots$ & $\ldots$ & $\ldots$ \\
\hline $\mathrm{Hd}$ & $0,12-0,22$ & $\ldots$ & $\ldots$ & $\ldots$ & $\ldots$ & $\ldots$ & $\ldots$ & $\ldots$ & $\ldots$ \\
\hline E1 & $0,22-0,40$ & 0 & 0 & 10 & 930 & 30 & 0 & 30 & Areia \\
\hline E2 & $0,40-0,60$ & 0 & 0 & 0 & 960 & 20 & 0 & 20 & Areia \\
\hline Bhsj 1 & $0,60-0,95$ & 0 & 0 & 0 & 930 & 20 & 20 & 30 & Areia \\
\hline Bhsj2 & $0,95-1,03$ & 0 & 0 & 10 & 950 & 10 & 0 & 30 & Areia \\
\hline $2 \mathrm{Cgj}$ & $1,03-1,40+$ & 0 & 0 & 10 & 690 & 70 & 100 & 130 & Areia franca \\
\hline
\end{tabular}

R14 - Espodossolo Ferrihumilúvico hidromórfico organossólico

\begin{tabular}{|c|c|c|c|c|c|c|c|c|c|}
\hline Ho & $0-0,07$ & $\ldots$ & $\ldots$ & $\ldots$ & $\ldots$ & $\ldots$ & $\ldots$ & $\ldots$ & $\ldots$ \\
\hline A & $0,07-0,14$ & 0 & 0 & 10 & 920 & 40 & 0 & 30 & Areia \\
\hline $\mathrm{E}$ & $0,14-0,23$ & 0 & 0 & 0 & 930 & 30 & 10 & 30 & Areia \\
\hline Bhsj & $0,23-0,30$ & 0 & 0 & 0 & 930 & 30 & 0 & 40 & Areia \\
\hline Bhsmj & $0,30-0,45$ & 0 & 0 & 60 & 890 & 10 & 0 & 40 & Areia \\
\hline $\mathrm{Cgj}$ & $0,45-0,60+$ & 0 & 0 & 0 & 890 & 40 & 0 & 70 & Areia \\
\hline
\end{tabular}

(1) MG: muito grossa (1-2 mm); G: grossa (0,5-1,0 mm); M: média $(0,25-0,50 \mathrm{~mm})$; F: fina $(0,10-0,25 \mathrm{~mm})$; MF: muito fina $(0,05-0,10 \mathrm{~mm})$. ...: Dados não disponíveis. 
Quadro 3. Dados químicos dos perfis de solos estudados na parcela permanente sob vegetação de mata de restinga do projeto BIOTA Parcelas Permanentes, Ilha do Cardoso, Cananéia (SP)

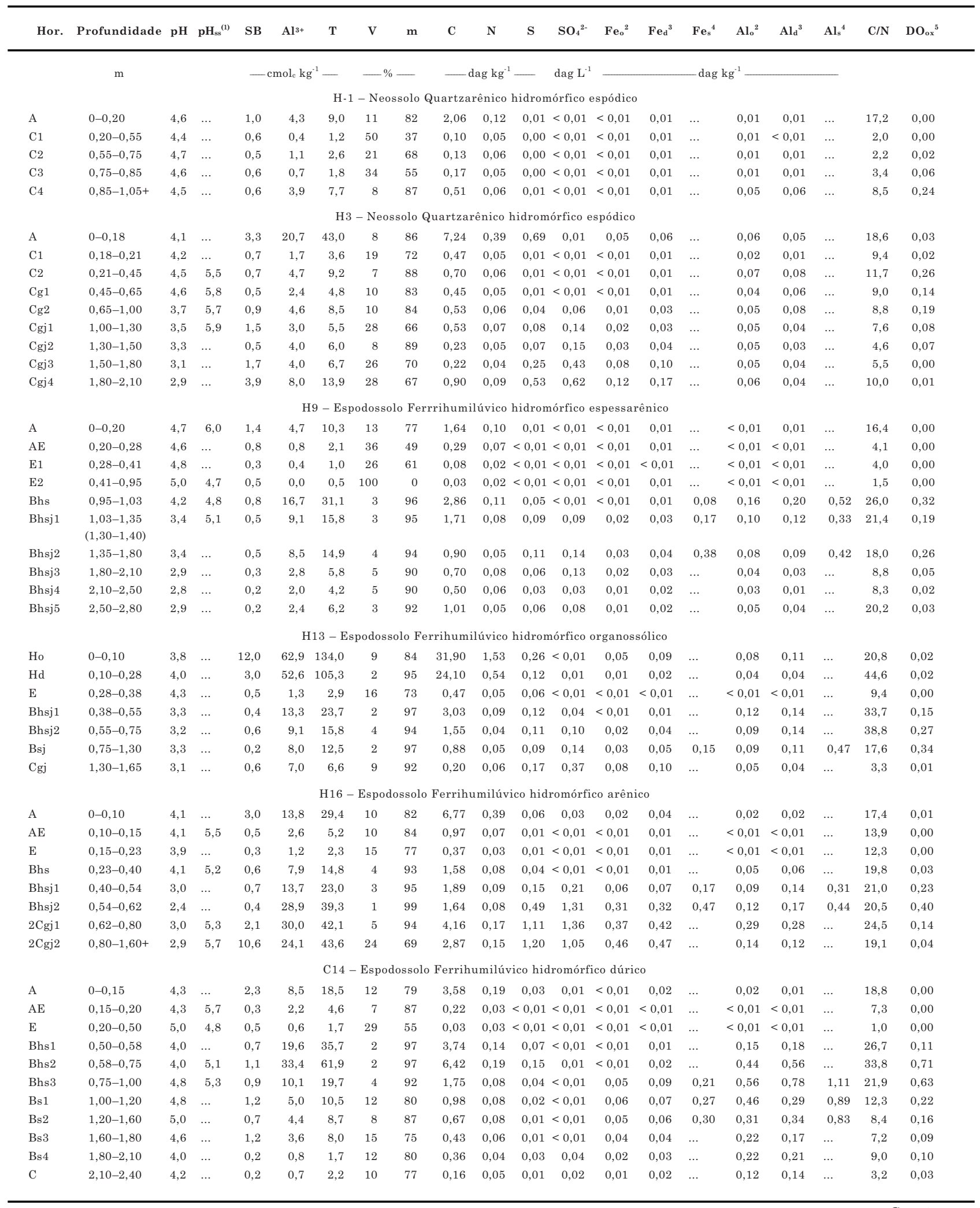




\section{Quadro 3. Continuação}

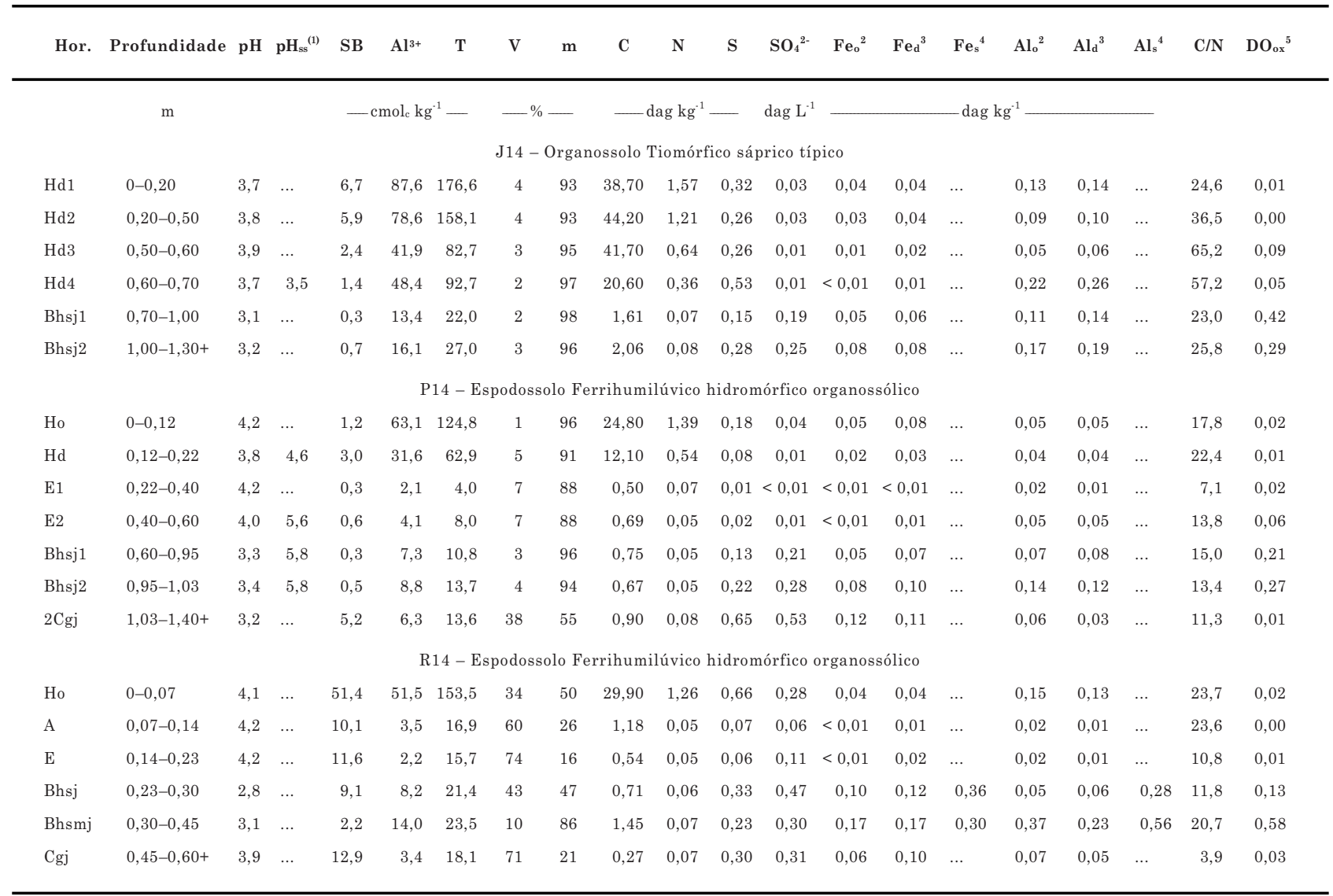

(1) $\mathrm{pH}_{\mathrm{ss}}: \mathrm{pH}$ obtido da solução do solo extraída in situ. ${ }^{(2)} \mathrm{Fe}_{\mathrm{o}}$ e $\mathrm{Al}_{\mathrm{o}}: \mathrm{Fe}$ e $\mathrm{Al}$ extraídos pelo oxalato; $\mathrm{Fe}_{\mathrm{d}}$ e $\mathrm{Al}_{\mathrm{d}}: \mathrm{Fe}$ e $\mathrm{Al}$ extraídos pelo ditionito-citrato. ${ }^{(3)} \mathrm{Fe}_{\mathrm{s}}$ e $\mathrm{Al}_{\mathrm{s}}$ : $\mathrm{Fe}$ e $\mathrm{Al}$ extraídos pelo ataque sulfúrico. ${ }^{(4)} \mathrm{DO}_{\mathrm{ox}}$ : densidade ótica obtida no extrato do oxalato a $430 \mathrm{~nm}$.
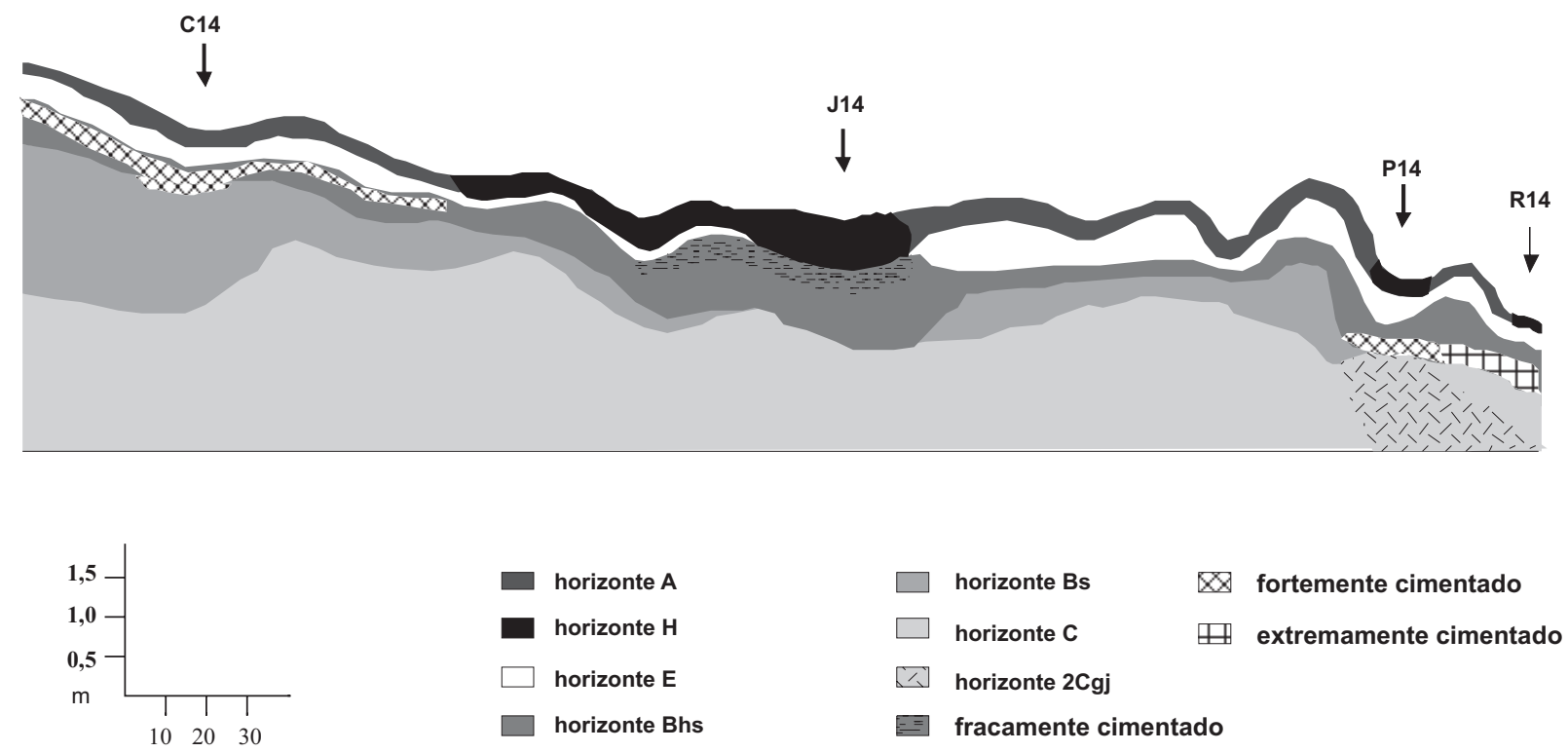

Figura 5. Estrutura da transeção 14 dos solos estudados sob vegetação de mata de restinga na Ilha do Cardoso, Cananéia (SP). 
(a)

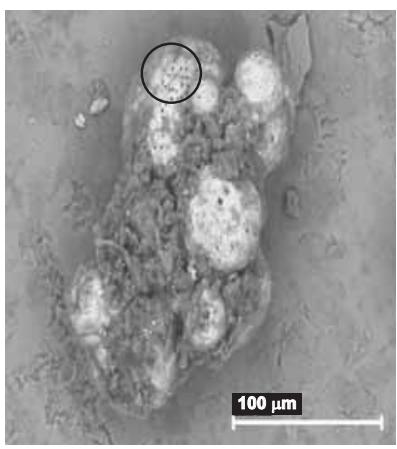

(b)

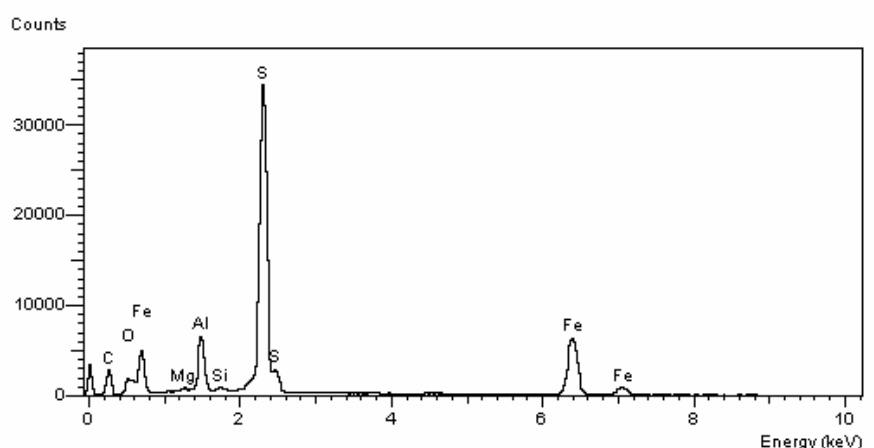

Figura 6. Microscopia eletrônica de varredura (a) e espectroscopia de energia dispersiva (b) de uma pirita do perfil H16 em estado avançado de oxidação, evidenciado pelos espaços vazios (destaque) e ausência de cristais bem definidos.

\section{DISCUSSÃo}

\section{Distribuição dos solos}

Os perfis H-1 e H3 (Figura 3) são os mais próximos ao mar e, conseqüentemente, mais jovens. Apresentaram algumas evidências da podzolização em profundidade, como suave escurecimento e valores ligeiramente mais elevados de $\mathrm{Fe}$ e $\mathrm{Al}$ nas extrações seletivas e nos valores obtidos na $\mathrm{DO}_{\mathrm{ox}}$. Contudo, não chegam a formar o horizonte espódico, sendo intermediários entre Neossolo Quartzarênico e Espodossolo e, por isso, classificados como Neossolo Quartzarênico hidromórfico espódico. O perfil H3 é sensivelmente mais desenvolvido que o $\mathrm{H}-1$, apresentandojá um delgado horizonte $\mathrm{C} 1$ transicional para E. Este horizonte está acima do tronco caído datado em 1.500 anos AP pelo ${ }^{14} \mathrm{C}$, o que evidencia o desenvolvimento deste horizonte após a queda deste, pelo processo de podzolização.

Nos perfis mais afastados do mar, a podzolização foi mais intensa e evidente. A estabilização do material sedimentado é pouco superior a 4.690 anos AP, o que se pode concluir com a datação em uma raiz morta do perfil H9, sendo contemporâneo ao nível máximo da Trangressão Santos, de cerca de 5.000 anos AP (Suguio \& Martin, 1978), permitindo esse maior desenvolvimento. A coloração do horizonte espódico apresentou, via de regra, valores e cromas baixos, principalmente no topo deste, tendendo a aumentar em profundidade, chegando a originar horizontes Bs. No entanto, esse aumento não foi acompanhado por aumentos expressivos no teor de $\mathrm{Fe}$ e, ou, $\mathrm{Al}$.

\section{Características químicas e físicas}

Os solos são arenosos, com predominância da fração areia fina devido ao próprio material de origem, composto essencialmente de areia fina a muito fina bem selecionada (Suguio, 1993; Villwock et al., 2005). $\mathrm{O}$ material de textura mais fina que ocorreu em dois perfis (horizontes 2Cgj dos perfis $\mathrm{H} 16$ e P14) é provavelmente fundo de canal ou baía, coberto por sedimentos arenosos com a elevação do nível do mar (Suguio \& Martin, 1978). Corrobora essa hipótese a ocorrência de pirita (Figura 6) neste horizonte glei, mineral que é formado somente sob condições redutoras e com fonte de sulfato (água do mar) e Fe (sedimentos de origem continental), o que ocorre nessas situações (Dent, 1986). Além disso, a forma framboidal da pirita é outro indicativo, já que é típica de ambientes marinhos rasos (Giblin, 1988). O fato de estas piritas apresentarem indícios de degradação indica que já não estão mais em condições estáveis.

Os Neossolos Quartzarênicos apresentaram ligeiro incremento nos teores de argila em profundidade, $o$ que pode ser atribuído à mistura com o material de textura mais fina, também de origem diferenciada, como no caso do material dos perfis H16 e P14, porém não chegando a apresentar horizonte com descontinuidade no material de origem ( $2 \mathrm{Cgj})$. $\mathrm{O}$ decréscimo do $\mathrm{pH}$ e aumento dos teores de $\mathrm{S}$ no perfil $\mathrm{H} 3$ corroboram essa hipótese.

Os baixos valores de $\mathrm{pH}$ de solos sob vegetação de restinga são comuns, visto que os solos se desenvolvem sob sedimentos arenosos originalmente pobres em bases. Cabe ressaltar, no entanto, que, comparandose a outros Espodossolos descritos na costa do Estado de São Paulo (Brasil, 1960; Rossi, 1999) e do Brasil (Gomes et al., 1998; Moura Filho, 1998; Gomes, 2002), os solos da Ilha do Cardoso apresentaram valores ainda mais baixos de $\mathrm{pH}$, o que indica que o material de origem subjacente aos depósitos praiais arenosos, que aparece em menor profundidade nos perfis $\mathrm{H} 16$ e P14, está ocorrendo sob todos os solos, influenciando os horizontes espódicos. Os valores mais baixos de $\mathrm{pH}$ da TFSA em relação aos da solução do solo e os teores de $\mathrm{S}$ total e $\mathrm{SO}_{4}{ }^{2-}$ mais elevados em profundidade na maioria dos solos, aliados ao odor característico de sulfetos detectado pelos pesquisadores no momento da coleta, confirmam essa hipótese. É importante observar que a maioria desses solos é arenosa, não 
apresentando capacidade-tampão, e qualquer quantidade de sulfetos nesse material afeta a acidez de maneira significativa.

Segundo Andriesse (1969), o material de origem pobre em nutrientes exerce papel fundamental na gênese de Espodossolos de regiões tropicais, induzindo o crescimento de espécies vegetais que produzem uma liteira pobre em bases e com relação $\mathrm{C} / \mathrm{N}$ elevada. Os horizontes $\mathrm{A}$ e $\mathrm{H}$ dos solos estudados apresentaram relações elevadas, maiores que 16 , chegando a valores maiores que 60 no Organossolo (perfil J14) (Quadro 3). Havlin et al. (2005) indicam que a relação $\mathrm{C} / \mathrm{N}$ de aproximadamente 20 é o limiar entre a imobilização e a mineralização, o que indica que nos solos estudados a mineralização é mínima ou não ocorre. O horizonte $\mathrm{E}$ tende a apresentar valores de $\mathrm{pH}$ mais elevados que os demais, por serem lavados e pobres em material orgânico - provável maior fonte de acidez destes solos (Gomes et al., 1998). O cátion dominante no complexo de troca é o $\mathrm{Al}$, resultando em solos álicos. A capacidade de troca catiônica $(\mathrm{T})$ varia muito, acompanhando os teores de carbono orgânico, já que este é o responsável por ela mesma nestes solos, compostos basicamente por areias que pouco contribuem com o valor T (Rossi \& Queiroz Neto, 2001), evidenciando a constituição orgânica da fração coloidal desses solos.

Quatro solos apresentaram teores de carbono elevados em superfície, mostrando horizontes de constituição predominantemente orgânica (horizonte hístico). O perfil J14, com $70 \mathrm{~cm}$ deste horizonte, foi o único classificado como solo orgânico, sendo denominado Organossolo Tiomórfico sáprico típico pelo SiBCS (Embrapa, 2006). Os perfis H13, P14 e R14 foram classificados como Espodossolo Ferrihumilúvico hidromórfico organossólico, por apresentarem menos de $40 \mathrm{~cm}$ de horizonte hístico. Estes solos ocorrem em áreas abaciadas da planície litorânea (Rossi, 1999); o perfil R14 ocorreu já na transição entre a vegetação de restinga e o manguezal.

\section{Hidromorfia e podzolização}

Nos solos estudados, a hidromorfia ocorre sempre em conjunto com a podzolização, o que mascara as feições redoximórficas, devido às colorações "espódicas" (Evans \& Mokma, 1996). Estes são os processos pedogenéticos dominantes na gênese desses solos e ocorrem em conjunto, sendo a podzolização dependente da hidromorfia. Andriesse (1969) já postulava que Espodossolos em regiões tropicais úmidas, mal drenados e sobre materiais de origem pobres, apesar da semelhança morfológica com Espodossolos de regiões mais frias, tinham outro mecanismo de formação, no qual a hidromorfia era fundamental no processo, devido à falta de drenagem, impedindo a água rica em material orgânico solúvel de sair do sistema. Uma evidência disso é o maior desenvolvimento do horizonte $\mathrm{E}$ nos locais mais elevados (antigas cristas de cordões arenosos) e o menor desenvolvimento deste horizonte nas zonas mais baixas (Figuras 4 e 5), onde a saturação é muito freqüente e, conseqüentemente, o horizonte espódico está mais próximo à superfície. Nesses locais mais baixos ocorre o horizonte hístico, e o horizonte $\mathrm{E}$, além de mais delgado, possui cor mais escura, com valores mais baixos, mostrando maior influência do lençol freático neste horizonte. Segundo Evans \& Monkma (1996), o horizonte $\mathrm{E}$ é o que mais reflete a influência da flutuação do lençol freático, onde ocorre o limite tanto de eluviação quanto de iluviação, e a atual quantidade de constituintes iluviados é pequena. Dessa forma, um horizonte $\mathrm{E}$ mais claro indica menor presença de material eluviado/iluviado, devido à menor oscilação do lençol.

Quanto aos Espodossolos, pode-se então definir dois tipos em função das características morfológicas. $\mathrm{O}$ primeiro apresentou hidromorfia mais acentuada, com formação de horizonte hístico, sendo representado pelos perfis H13, P14 e R14, além do perfil H16, que, apesar de não chegar a formar horizonte hístico, apresentou o horizonte $2 \mathrm{Cgj}$ e teores elevados de carbono no horizonte A. O segundo é representado pelos perfis C14 e H9, com hidromorfia menos acentuada. Assim, o primeiro tipo apresentou horizonte E mais delgado, cores com valores e cromas mais baixos, devido à maior presença do lençol freático neste horizonte. O segundo tipo seria representado pelos perfis $\mathrm{H} 9$ e C14, em posições um pouco mais elevadas, com horizontes $\mathrm{E}$ mais claros e limite abrupto para o horizonte espódico.

\section{Classificação}

O perfil H9 (Figura 3b), que ocorreu em uma pequena elevação, correspondente a uma antiga crista de cordão arenoso, apresentou maior espessura de horizonte E, corroborando a hipótese de que o lençol freático exerceu papel decisivo na profundidade da ocorrência do horizonte espódico. Este perfil foi classificado como Espodossolo Ferrihumilúvico hidromórfico espessarênico, devido à espessura de horizontes com textura arenosa $(>100 \mathrm{~cm})$. O perfil C14 (Figura 3e) também apresentou um horizonte $\mathrm{E}$ bem desenvolvido, embora menos espesso, e um horizonte endurecido, que, segundo a nova versão do SiBCS (Embrapa, 2006), pode ser classificado como ortstein, o que não ocorria com a versão anterior do SiBCS (Embrapa, 1999). Foi então classificado como Espodossolo Ferrihumilúvico hidromórfico dúrico. $\mathrm{O}$ perfil H16 (Figura 3d), apesar de não possuir horizonte hístico, apresentou um horizonte superficial relativamente rico em $\mathrm{MO}$ e um horizonte glei com presença de pirita a $62 \mathrm{~cm}$ de profundidade. Foi classificado como Espodossolo Ferrihumilúvico hidromórfico arênico, embora justificasse a inclusão de uma denominação indicativa da possibilidade de acidificação deste solo quando drenado, como será discutido adiante. O perfil R14, apesar de apresentar ortstein, não foi classificado como "dúrico" no quarto nível categórico, devido à precedência da denominação "organossólico". 
Apesar de não apresentarem valores elevados de Fe em todas as extrações e devido à ausência de critério específico do SiBCS (Embrapa, 2006), em que não se utilizam critérios químicos quantitativos para identificação de horizontes Bhs e Bs, todos os Espodossolos foram classificados como Espodossolo Ferrihumilúvico. Houve melhora, entretanto, em relação à versão anterior do SiBCS (Embrapa, 1999), pois já se define que, para ser classificado como Bhs, deve-se ter "iluviação expressiva de $\mathrm{MO}$ e $\mathrm{Fe}$ " e "quantidades significativas de $\mathrm{Fe}$ e $\mathrm{Al}$ extraídos pelo oxalato", com a ressalva de que "os limites ainda devem ser estabelecidos para os solos brasileiros". Até a versão anterior do SiBCS (Embrapa, 1999), eram levadas em consideração duas características: cor e teor de $\mathrm{Fe}$ e $\mathrm{Al}$ extraídos pelo ataque sulfúrico, sem precisar qual dos dois critérios (químico ou morfológico) tinha precedência na determinação do horizonte. No caso do horizonte Bs, apenas o valor e o croma (ambos maiores ou iguais a 3 ) podiam determinar se este horizonte é Bs. Isso permanece, com a ressalva de que se deve criar um valor para definir o quanto pode ser considerado "acúmulo de $\mathrm{Fe}$ e Al". O perfil C14 ilustra bem esse problema, mostrando horizontes com teores baixos de Fe (horizontes Bs3 e Bs4), chegando a $0,02 \mathrm{dag} \mathrm{kg}^{-1}$ de Fe extraído pelo ditionito e 0,01 dag $\mathrm{kg}^{-1}$ extraído pelo oxalato, os quais foram classificados como Bs. Considerou-se que, além do critério de cor, ocorreu acúmulo de $\mathrm{Fe}$ em profundidade, apesar dos valores baixos.

Na versão do SiBCS de 2006 ficaram mais claras as diferentes designações de horizontes espódicos. O quadro 4 mostra a classificação dos Espodossolos segundo as duas edições do SiBCS. Apesar de definir os horizontes Bh, Bhs e Bs de forma mais precisa, o SiBCS atual ainda apresenta problemas no que diz respeito ao critério a ser utilizado na definição de cada um deles, como discutido anteriormente.

Os valores da densidade ótica do extrato do oxalato foram condizentes com os esperados pela classificação norte-americana como um dos requisitos, não excludente, para identificação de material espódico (Estados Unidos, 1999), apresentando valores > 0,25 ou pelo menos o dobro em relação ao horizonte suprajacente. Contudo, outro critério, também não excludente, no qual o teor de $\mathrm{Al}_{0}$ somado a $1 / 2$ do teor de $\mathrm{Fe}_{0}$ deve ser maior ou igual a $0,50 \mathrm{dag} \mathrm{kg}^{-1}$, ocorreu para apenas um horizonte. Ao que tudo indica, as determinações químicas utilizadas na classificação americana não parecem adequados aos Espodossolos da costa brasileira, fato observado também por Moura Filho (1998).

Outra consideração que deve ser feita no que diz respeito ao SiBCS (Embrapa, 2006) é sobre a subordem Espodossolo Ferrilúvico, que denota migração de $\mathrm{Fe}$ sem MO, o que contradiz o processo de podzolização. Um solo com migração de Fe somente sugere a predominância de processos como a ferrólise, gleização e, ou, plintitização.

\section{Materiais sulfídricos}

A possível presença de materiais sulfídricos não está prevista na ordem Espodossolos no SiBCS. Por esse motivo, na classificação atualizada (Quadro 4), a denominação "tiônico" deveria ser adicionada no quarto nível categórico do perfil H16, em substituição ao "arênico". No caso dos perfis H13 e P14, por apresentarem horizonte hístico, eles poderiam ser classificados como "organossólico tiônico" no quarto nível categórico, e o perfil R14, como "organossólico dúrico tiônico". Os demais solos, por apresentarem materiais sulfídricos abaixo dos $100 \mathrm{~cm}$, não tiveram essa denominação. Outra alternativa que poderia ser adotada futuramente pelo SiBCS seria usar alguma denominação indicativa de descontinuidade no material de origem do solo, evitando-se assim utilizar uma denominação de processos não relacionados pedogeneticamente. Também poderiam ser utilizados no quinto e sexto níveis categóricos, embora sejam características importantes e que normalmente são designadas no quarto nível.

\section{Considerações finais}

Os solos encontrados apresentaram o processo de podzolização em diferentes estádios, que estão relacionados principalmente à estabilização do sedimento arenoso a partir da instalação da vegetação.

Quadro 4. Classificação dos Espodossolos segundo o SiBCS anterior (Embrapa, 1999) e o atual (Embrapa, 2006)

\begin{tabular}{lll}
\hline Solo & SiBCS (1999) & SiBCS (2006) \\
\hline H9 & Espodossolo Ferrocárbico hidromórfico arênico & Espodossolo Ferrihumilúvico hidromórfico espessarênico \\
H13 & Espodossolo Ferrocárbico hidromórfico hístico & Espodossolo Ferrihumilúvico hidromórfico organossólico \\
H16 & Espodossolo Ferrocárbico hidromórfico típico & Espodossolo Ferrihumilúvico hidromórfico arênico \\
C14 & Espodossolo Ferrocárbico hidromórfico típico & Espodossolo Ferrihumilúvico hidromórfico dúrico \\
P14 & Espodossolo Ferrocárbico hidromórfico hístico & Espodossolo Ferrihumilúvico hidromórfico organossólico \\
R14 & Espodossolo Ferrocárbico hidromórfico hístico & Espodossolo Ferrihumilúvico hidromórfico organossólico
\end{tabular}


Entre os Espodossolos, a microtopografia exerceu papel fundamental na morfologia e, conseqüentemente, na classificação dos solos. Os que estavam em posições mais abaciadas apresentaram menor espessura de horizonte E e maiores teores de MO na superfície, chegando a formar Organossolos, enquanto os que estavam em posições mais elevadas mostraram horizonte $\mathrm{E}$ mais espesso e com tons mais claros. Isso ocorreu devido à hidromorfia, que exerce papel fundamental na gênese desses solos, impedindo a saída da água rica em MO dissolvida do sistema.

A segunda edição do SiBCS (Embrapa, 2006) melhorou os critérios de definição do horizonte espódico, porém apresenta ainda algumas carências, que devem ser sanadas com a realização de mais estudos de correlação de Espodossolos no País. Entretanto, na chave de classificação, a criação da subordem "Espodossolo Ferrilúvico" é questionável, pois elimina um elemento-chave, a MO iluvial - do processo de podzolização.

\section{CONCLUSÕES}

1. Os Espodossolos estudados são holocênicos, formados após estabilização dos sedimentos da deposição regressiva da Transgressão Santos.

2. A podzolização está intimamente ligada à oscilação do lençol freático.

3. O SiBCS deve adotar um critério químico quantitativo (relativo e, ou, absoluto) para denotar a presença de Fe no horizonte espódico; determinar a precedência deste critério em relação ao da cor; e inserir a denominação "tiônico" no quarto nível categórico para a ordem Espodossolo.

4. A ocorrência de materiais sulfídricos nesses solos está relacionada ao material subjacente aos depósitos de cordões arenosos, que é mais fino, rico em sulfetos e depositado previamente em situação de fundo de canal. Essa influência se deu de forma direta (horizontes 2Cgj dos perfis H16 e P14) ou pela oscilação do lençol freático, trazendo sulfetos aos horizontes arenosos, os quais têm baixa capacidade-tampão.

\section{AGRADECIMENTOS}

À Coordenação de Aperfeiçoamento de Pessoal de Nível Superior (CAPES), pelo financiamento do doutorado-sanduíche do primeiro autor; e à FAPESP, através do projeto: "Diversidade, dinâmica e conservação em florestas do Estado de São Paulo: 40 ha de parcelas permanentes- BIOTA", pelo apoio financeiro. Ao Instituto Florestal do Estado de São Paulo e ao Instituto Oceanográfico da USP pelas facilidades oferecidas durante os trabalhos de campo.

\section{LITERATURA CITADA}

ANDRIESSE, J.P. Study of the environmental and characteristics of tropical podzols in Sarawak (EastMalasia). Geoderma, 2:201-227, 1969.

ARAÚJO, D.S.D. \& LACERDA, L.D. A natureza das restingas. Ci. Hoje, 6:42-48, 1987.

BOULET, R.; CHAUVEL, A.; HUMBEL, F.X. \& LUCAS, Y. Analyse structurale et cartographie en pédologie I - Prise em compte de l'organisation bidimensionnelle de la couverture pédologique: Les études de topósequences et leurs principaux apports à la connaissance des sols. Cashier ORSTOM. Série Pédol., 19:309-321, 1982.

BRASIL. Ministéro da Agricultura. Centro Nacional de Ensino e Pesquisas Agronômicas. Serviço Nacional de Pesquisas Agronômicas. Comissão de Solos. Levantamento de reconhecimento dos solos do Estado de São Paulo: Contribuição à carta de solos do Brasil. Rio de Janeiro, 1960. 634p. (Boletim, 12)

BRAVARD, S. \& RIGHI, D. Geochemical differences in an oxisol-spodosol toposequence of Amazonia (Brazil). Geoderma, 44:29-42, 1989.

BUURMAN, P.; LAGEN, B. \& VELTHORST, E.J. Manual of soil and water analysis. Leiden, Backhuys Publishers Leiden, 1996. 314p.

CHESWORTH, W. \& MACÍAS, F. pe, pH and podzolization. Am. J. Sci., 285:128-146, 1985.

COURCHESNE, F. \& HENDERSHOT, W.H. La genèse des podzols. Géogr. Pphys. Quarter., 51:235-250, 1997.

DENT, D. Acid sulphate soils: A baseline for research and development. Wageningen, International Institute for Land Reclamation and Improvement, 1986. 203p.

DUBROUECQ, D. \& VOLKOFF, B. From Oxisols to Spodosols and Histosols: Evolution of the soil mantles in the Rio Negro basin (Amazonia). Catena, 32:245-280, 1998.

EMPRESA BRASILEIRA DE PESQUISA AGROPECUÁRIA EMBRAPA. Centro Nacional de Pesquisa de Solos. Manual de métodos de análise de solo. 2.ed. Rio de Janeiro, 1997. $212 \mathrm{p}$.

EMPRESA BRASILEIRA DE PESQUISA AGROPECUÁRIA EMBRAPA. Centro Nacional de Pesquisa de Solos. Sistema brasileiro de classificação de solos. Rio de Janeiro, 1999. 412p.

EMPRESA BRASILEIRA DE PESQUISA AGROPECUÁRIA EMBRAPA. Centro Nacional de Pesquisa de Solos. Sistema brasileiro de classificação de solos. Rio de Janeiro, 2006. 306p.

ESTADOS UNIDOS. Department of Agriculture. Soil Survey Division. Soil Conservation Service. Soil Survey Staff. Soil taxonomy: A basic system of soil classification for making and interpreting soils surveys. 2.ed. Washington, 1999. 869p. 
ESTADOS UNIDOS. Department of Agriculture. Soil Survey Division. Soil Conservation Service. Soil Survey Staff. Keys to soil taxonomy. 6.ed. Washington, 1994. 306p.

EVANS, C.V. \& MOKMA, D.L. Sandy wet Spodosols: Water tables, chemistry, and pedon partioning. Soil Sci. Soc. Am. J., 60:1495-1501, 1996.

FOOD AND AGRICULTURE ORGANIZATION OF THE UNITED NATIONS - FAO. World reference base for soil resources. Paris, UNESCO, 1994. 161p.

GIBLIN, A.E. Pyrite formation in marshes during early diagenesis. Geomicrobiol. J., 6: 77-97, 1988.

GOMES, F.H. Caracterização de solos de manguezais e de restinga no município de Ilhéus-Bahia. Viçosa, MG, Universidade Federal de Viçosa, 2002. 96p. (Tese de Mestrado)

GOMES, F.H. \& VIDAL-TORRADO, P. Mapa ultradetalhado de solos da parcela sob restinga do projeto "parcelas permanentes" do BIOTA. In: SIMPÓSIO INTERNO DO PROJETO: DIVERSIDADE, DINÂMICA E CONSERVAÇÃO EM FLORESTAS DE SÃO PAULO: 40 HA DE PARCELAS PERMANENTES, 3., Piracicaba, 2005. Resumos. Piracicaba, Escola Superior de Agricultura Luiz de Queiroz, 2005.

GOMES, J.B.; RESENDE, M.; REZENDE, S.B. \& MENDONÇA, E.S. Solos de três áreas de restinga. I. Morfologia, caracterização e classificação. Pesq. Agropec. Bras., 33:1907-1919, 1998.

HAVLIN, J.L.; TISDALE, S.L.; BEATON, J.D. \& NELSON, W.L. Soil fertility and fertilizers: An introduction to nutrient management. 7.ed. Upple Side River, Pearson Educator, 2005. 515p.

LEÃO, Z.M.A.N. \& DOMINGUEZ, J.M.L. Tropical coast of Brazil. Mar. Poll. Bull., 41:112-122, 2000.

LUCAS, Y.; BOULET, A.; CHAUVEL, A. \& VEILLON, L. Systèmes sols ferralitiques-podzols em région amazonienne. In: RIGHI, D. \& CHAUVEL, A., eds. Podzols et podzolisation. Paris, Institute Nacional de la Recherche Agronomique, 1987. p.53-65.

LUNDSTRÖM, U.S.; van BREEMEN, N. \& BAIN, D.C. The podzolization process. A review. Geoderma, 94:91-107, 2000 .

MAFRA, A.L.; MIKLÓS, A.A.W.; VOLKOFF, B. \& MELFI, A.J. Pedogênese numa seqüência Latossolo Espodossolo na região do Alto Rio Negro, Amazonas. R. Bras. Ci. Solo, 26:381-394, 2002.

MELO, M.R.F. \& MANTOVANI, W. Composição florística e estrutura fitossociológica da mata atlântica de encosta na Ilha do Cardoso (Cananéia, SP. Brasil). B. Inst. Bot., 9:107158, 1994.
MOURA FILHO, G. Caracterização e uso de solos arenosos associados à foz do Rio São Francisco, no litoral sul de Alagoas. Viçosa, MG, Universidade Federal de Viçosa, 1998. 169p. (Tese de Doutorado)

OLIVEIRA, J.B.; JACOMINE, P.K.T. \& CAMARGO, M.N. Classes gerais de solos do Brasil: Guia auxiliar para seu reconhecimento. 2.ed. Jaboticabal, FUNEP, 1992. 201p.

PESSENDA, L.C.R. \& CAMARGO, P.B. Datação radiocarbônica de amostras de interesse arqueológico e geológico por espectroscopia de cintilação líquida de baixa radiação de fundo. Química Nova, 4:98-103, 1991.

PETRI, S. \& FÚLFARO, V.J. Nota sobre a geologia e terraços marinhos da Ilha do Cardoso. Notícias Geomorfol., 10:21$31,1970$.

ROSSI, M. Fatores formadores da paisagem litorânea: A bacia do Guaratuba, São Paulo - Brasil. São Paulo, Universidade de São Paulo, 1999. 159p. (Tese de Doutorado)

ROSSI, M. \& QUEIROZ NETO, J.P. Os solos como indicadores das relações entre sedimentos continentais e marinhos na planície costeira: Rio Guaratuba (SP). R. Bras. Ci. Solo, 25:113-120, 2001.

SANTOS, H.G.; COELHO, M.R.; ANJOS, L.H.; JACOMINE, P.K.T.; OLIVEIRA, V.A.; LUMBRERAS, J.F.; OLIVEIRA, J.B.; CARVALHO, A.P. \& FASOLO, P.J. Propostas de revisão e atualização do sistema brasileiro de classificação de solos. Rio de Janeiro, Embrapa, Centro Nacional de Pesquisa de Solos, 2003. 56p.

SANTOS, R.D.; LEMOS, R.C.; SANTOS; H.G.; KER, J.C. \& ANJOS, L.H.C. Manual de descrição e coleta de solo no campo. 5.ed. Viçosa, MG, Sociedade Brasileira de Ciência do Solo, 2005. 100p.

SILVA, S.M. Diagnósticos das restingas do Brasil. In: WORKSHOP DE AVALIAÇÃO E AÇÕES PRIORITÁRIAS PARA CONSERVAÇÃO DA BIODIVERSIDADE DA ZONA COSTEIRA E MARINHA, 1999, Porto Seguro. Anais eletrônicos. Porto Seguro, Fundação BIO RIO, 1999. Disponível em: <http:// www.bdt.fat.org.br/workshop/costa/restinga/> Acesso em: 10 abril de 2002 .

SUGUIO, K. A Ilha do Cardoso no contexto geomorfológico do litoral sul paulista da Província Costeira. In: SIMPÓSIO DE ECOSSISTEMAS DA COSTA BRASILEIRA, 3., Serra Negra, 1993. Anais. Serra Negra, ACIESP, 1993. p.154171.

SUGUIO, K. \& MARTIN, L. Formações quaternárias marinhas do litoral paulista e sul fluminense. In: INTERNATIONAL SYMPOSIUM ON COASTAL EVOLUTION IN THE QUATERNARY, 1., São Paulo, 1978. Anais. São Paulo, IGUSP, 1978. 55p.

SUGUIO, K. \& TESSLER, M.G. Planícies de cordões litorâneos quaternários do Brasil: Origem e nomenclatura. In: LACERDA, L.D.; ARAÚJO, D.S.D.; CERQUEIRA, R. \& TURQ, B. Restingas: Origem, estrutura e processos. Niterói, CEUFF, 1984. p.15-26. 
van BREEMEN, N. \& BUURMAN, P. Soil formation. 2.ed. Dordrecht, Kluwer Academic Publishers, 2002. 404p.
VILLWOCK, J.A.; LESSA, G.C.; SUGUIO, K.; ANGULO, R.J. \& DILLENBURG, S.R. Geologia e geomorfologia de regiões costeiras. In: SOUZA, C.R.G.; SUGUIO, K.; OLIVEIRA, A.M.S. \& OLIVEIRA, P.E., eds. Quaternário do Brasil. Ribeirão Preto, Holos, 2005. p.94-113. 